\title{
From 2D to 1D Electronic Dimensionality in Halide Perovskites with Stepped and Flat Layers Using Propylammonium as a Spacer
}

Justin M. Hoffman, ${ }^{1}$ Xiaoyang Che, ${ }^{3}$ Siraj Sidhik, ${ }^{2}$ Xiaotong Li, ${ }^{1}$ Ido Hadar, ${ }^{1}$ Jean-Christophe Blancon, ${ }^{2}$ Hisato Yamaguchi, ${ }^{3}$ Mikaël Kepenekian, ${ }^{4}$ Claudine Katan, ${ }^{4}$ Jacky Even, ${ }^{5}$ Constantinos C. Stoumpos, ${ }^{1}$ Aditya D. Mohite ${ }^{2}$ and Mercouri G. Kanatzidis ${ }^{1 *}$

E-mail: m-kanatzidis@northwestern.edu

${ }^{1}$ Department of Chemistry, Northwestern University, Evanston, IL 60208, United States

${ }^{2}$ Department of Chemical and Biomolecular Engineering, Rice University, Houston, Texas 77005, United States

${ }^{3}$ Los Alamos National Laboratory, Los Alamos, NM 87545, United States

${ }^{4}$ Univ Rennes, ENSCR, INSA Rennes, CNRS, ISCR (Institut des Sciences Chimiques de Rennes) - UMR 6226, Rennes F-35000, France

${ }^{5}$ Univ. Rennes, INSA Rennes, CNRS, Institut FOTON - UMR 6082, Rennes F-35000, France

\begin{abstract}
Two-dimensional (2D) hybrid halide perovskites are promising in optoelectronic applications, particularly solar cells and light emitting devices (LEDs), and for their increased stability compared to 3D perovskites. Here, we report a new series of structures using propylammonium $\left(\mathrm{PA}^{+}\right)$which results in a series of Ruddlesden-Popper (RP) structures with the formula $(\mathrm{PA})_{2}(\mathrm{MA})_{\mathrm{n}-1} \mathrm{~Pb}_{\mathrm{n}} \mathrm{I}_{3 \mathrm{n}+1}(\mathrm{n}=3,4)$ and a new homologous series of "step-like" (SL) structures where the $\mathrm{PbI}_{6}$ octahedra connect in a corner- and face-sharing motif with the general formula $(\mathrm{PA})_{2 \mathrm{~m}+4}(\mathrm{MA})_{\mathrm{m}-2} \mathrm{~Pb}_{2 \mathrm{~m}+1} \mathrm{I}_{7 \mathrm{~m}+4}(\mathrm{~m}=2,3,4)$. The RP structures show a blue-shift in bandgap for decreasing $\mathrm{n}(1.90 \mathrm{eV}$ for $\mathrm{n}=4$ and $2.03 \mathrm{eV}$ for $\mathrm{n}=3)$ while the SL structures have an even greater blue-shift (2.53 eV for $\mathrm{m}=4,2.74 \mathrm{eV}$ for $\mathrm{m}=3$, and $2.93 \mathrm{eV}$ for $\mathrm{m}=2)$. DFT calculations show that, while the RP structures are electronically $2 \mathrm{D}$ quantum wells, the SL structures are electronically 1D quantum wires with chains of corner-sharing octahedra "insulated" by blocks of face-sharing octahedra. Dark measurements for RP crystals show high resistivity perpendicular to the layers $\left(10^{11} \Omega \cdot \mathrm{cm}\right)$ but a lower resistivity parallel to them $\left(10^{7}\right.$ $\Omega \cdot \mathrm{cm})$. The SL crystals have varying resistivity in all three directions, confirming both RP and SL crystals' utility as anisotropic electronic materials. The RP structures show strong photoresponse, whereas the SL materials exhibit resistivity trends that are dominated by ionic
\end{abstract}


transport and no photoresponse. Solar cells were made with $n=3$ giving an efficiency of $7.04 \%$ (average $6.28 \pm 0.65 \%$ ) with negligible hysteresis.

Keywords: solar cell, photovoltaic, quantum confinement, light emitting diode, thin films, perovskitoid, photoluminescence 


\section{Introduction}

Halide inorganic-organic perovskites have shown remarkable capabilities to be used in a wide variety of optoelectronic devices. ${ }^{1-11}$ Two-dimensional (2D) halide perovskites are of particular interest because of increased stability in air and light, compared to the heavily studied 3D perovskites, while maintaining properties conducive to making high-efficiency optoelectronic devices. ${ }^{12-20}$ These materials derive from the $3 \mathrm{D} \mathrm{AMX}_{3}$, halide perovskites, in which $\mathrm{A}^{+}$must be $\mathrm{CH}_{3} \mathrm{NH}_{3}{ }^{+}\left(\mathrm{MA}^{+}\right), \mathrm{HC}\left(\mathrm{NH}_{2}\right)_{2}{ }^{+}\left(\mathrm{FA}^{+}\right)$, or $\mathrm{Cs}^{+}, \mathrm{M}^{2+}$ is generally $\mathrm{Pb}^{2+}, \mathrm{Sn}^{2+}$, or $\mathrm{Ge}^{2+}$, and $\mathrm{X}^{-}$is $\mathrm{Cl}^{-}$, $\mathrm{Br}^{-}$, or $\mathrm{I}^{-}$. When larger hydrophobic cations are used in the synthesis, new phases of perovskites form which show lower dimensionality and significantly improved moisture stability. ${ }^{21}$

Commonly seen are $2 \mathrm{D}$ sheets where the $3 \mathrm{D}$ perovskite structure is cut along the $<100>$ plane such as with the most commonly employed cations phenylethylammonium (PEA) $)^{12,17,22}$ or butylammonium (BA) ${ }^{13,15}$ among others, which act as spacers between the forming slabs. ${ }^{23-25}$ These two cases along with other less studied ones ${ }^{26}$ use monoamines to form the RuddlesdenPopper (RP) perovskites with the general formula $\left(A^{\prime}\right){ }_{2} A_{n-1} M_{n} X_{3 n+1}$ (in which $A^{\prime}$ is the large spacing cation). ${ }^{27}$ Here, $\mathrm{n}$ refers to the thickness of the layers in units of $\left[\mathrm{MX}_{6 / 2}\right]^{-}$octahedra. Other types of $<100>$-oriented perovskites include Dion-Jacobson (DJ) perovskites using certain diamines with the formula (A') $\mathrm{A}_{\mathrm{n}-1} \mathrm{M}_{\mathrm{n}} \mathrm{X}_{3 \mathrm{n}+1},{ }^{28}$ alternating cations in the interlayer space (ACI) with the formula $\left(\mathrm{A}^{\prime}\right)_{2} \mathrm{~A}_{\mathrm{n}-1} \mathrm{M}_{\mathrm{n}} \mathrm{X}_{3 \mathrm{n}+1},{ }^{29-30}$ and alkyl diammonium based with the formula $\left(\mathrm{H}_{3} \mathrm{~N}\left(\mathrm{CH}_{2}\right)_{\mathrm{n}} \mathrm{NH}_{3}\right) \mathrm{A}_{\mathrm{n}-1} \mathrm{M}_{\mathrm{n}} \mathrm{X}_{3 \mathrm{n}+1} \cdot{ }^{31}$ Cases where the cut is along the $<110>$ plane have been documented as well, ${ }^{25,}{ }^{32-37}$ such as for $\left(\mathrm{NH}_{2} \mathrm{C}(\mathrm{I})=\mathrm{NH}_{2}\right)_{2}$, where the organic I atom interacts strongly with the I atoms at the edges of the inorganic layer along the $<110>$ plane, thus stabilizing this uncommon structural perovskite type. ${ }^{38-39} \mathrm{~A}$ few examples also exist of perovskites being cleaved along the $<111>$ plane, for example with the trivalent metals in metal 
deficient $\mathrm{A}_{3} \mathrm{M}_{2} \mathrm{X}_{9}$ perovskites. ${ }^{39-40}$ The formulas for each of the structure types are shown in a hierarchal manner in Scheme 1 using the variables $\mathrm{n}, \mathrm{m}$, and q to indicate the different orientation of the octahedra. All these 2D materials are semiconductors that form natural quantum wells between the alternating organic and inorganic layers, forcing spatial and dielectric confinement of electron-hole pairs within the 2D perovskite plane..$^{25}$ These materials can be chemically tuned to give specific layer thickness corresponding to $\mathrm{n}$ in the general chemical formula and can attain different electronic states and bandgaps. ${ }^{41}$ This allows further

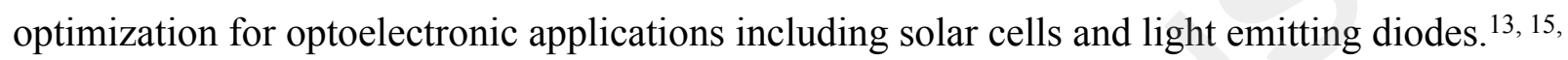
$42-43$

Certain intermediate size cations, that are too large to form a 3D perovskite and too small to intercalate between 2D perovskite sheets, can lead to unique structure types. Some of these cations lead to structures which maintain 3D connectivity. For example, in the case of the tin iodide system, several 3D tin-based hexagonal perovskites with the formula ( $\left.\mathrm{A}^{\prime}\right) \mathrm{SnI}_{3}$ have been reported in which the octahedra connect in both the typical corner-sharing fashion as well as a face-sharing fashion. ${ }^{44}$ This is done by using $\mathrm{EA}^{+}\left(\mathrm{CH}_{3} \mathrm{CH}_{2} \mathrm{NH}_{3}\right)^{+}, \mathrm{GA}^{+}\left(\mathrm{C}\left(\mathrm{NH}_{2}\right)_{3}^{+}\right), \mathrm{ACA}^{+}$ $\left(\mathrm{CH}_{3} \mathrm{C}\left(\mathrm{NH}_{2}\right)_{2}\right)$, and $\mathrm{IM}^{+}\left(\mathrm{C}_{3} \mathrm{~N}_{2} \mathrm{H}_{5}\right)$ as spacing cations. These are not proper perovskites because they do not feature exclusively corner-sharing octahedra and in order to distinguish them from perovskites, they are referred to as perovskitoids. ${ }^{44}$ Other examples of 3D structure types with intermediate cations include the so-called "hollow" perovskites in which the cation replaces metal octahedra while maintaining corner-sharing 3D connectivity. A disordered structure can be stabilized by shorter diamines such as in (en)MAMI $(\mathrm{M}=\mathrm{Sn}, \mathrm{Pb})^{45-46}$ and $(\mathrm{PN} / \mathrm{TN}) \mathrm{FASnI}_{3}(\mathrm{PN}$ $=$ propylenediammonium; $\mathrm{TN}=$ trimethylenediammonium $)^{47}$ while an ordered structure is seen with alkanolamines such as ethanolamine. ${ }^{48}$ The same tendencies toward the disruption of the 
inorganic lattice can be seen in the 2D materials. ${ }^{49-50}$ For example, materials such as $(\mathrm{PPA})_{3} \mathrm{~Pb}_{2} \mathrm{I}_{7}$ and $(\mathrm{PBA})_{3} \mathrm{~Pb}_{2} \mathrm{I}_{7}\left(\mathrm{PPA}^{+}=\mathrm{C}_{6} \mathrm{H}_{5}\left(\mathrm{CH}_{2}\right)_{3} \mathrm{NH}_{3}{ }^{+}\right.$and $\left.\mathrm{PBA}^{+}=\mathrm{C}_{6} \mathrm{H}_{5}\left(\mathrm{CH}_{2}\right)_{4} \mathrm{NH}_{3}{ }^{+}\right)$, whose alkyl chain length in these phenylalkylammonium cations varies, can also induce the formation of structures with mixed edge-, face-, and/or corner-sharing. ${ }^{51}$ These types of materials are stabilized using intermediate cations but are less explored. Furthermore, 1D perovskitoids derived from the $\mathrm{BaNiO}_{3}$ structure type have fully face-sharing connectivity ${ }^{44}$ while other $1 \mathrm{D}$ halide materials have mixed-sharing connectivity as well ${ }^{52}$ such as $\left(\mathrm{C}_{6} \mathrm{H}_{5} \mathrm{CH}_{2} \mathrm{NH}_{3}\right)_{4} \mathrm{~Pb}_{5} \mathrm{I}_{14} \cdot 2 \mathrm{H}_{2} \mathrm{O}$ which has corner- and edge-sharing connectivity. ${ }^{53}$ The shortest spacer length in the RP family which has been studied crystallographically is the butylammonium cation (four carbon chain length). Although one expects longer molecules to also stabilize this $2 \mathrm{D}$ halide perovskite family by expanding the inorganic layer spacing, ${ }^{54}$ it is interesting to consider how short the spacer can get before we observe some sort of structural instability. Such destabilization could arise for example from the inorganic layers being pulled too close together and steric repulsion becoming dominant.

Here, we present a new series of materials using propylammonium (PA) chosen specifically because it is the shortest spacer cation among the n-alkylammonium family (three carbon chain length) that can stabilize a perovskite in order to test the limits of phase formation in the RP 2D $(\mathrm{PA})_{2}(\mathrm{MA})_{\mathrm{n}-1} \mathrm{~Pb}_{\mathrm{n}} \mathrm{I}_{3 \mathrm{n}+1}$ perovskite family. We find that the " $\mathrm{n}=1$ " and " $\mathrm{n}=2$ " members cannot be formed, but instead a new series of step-like (SL) structures forms. In this series, the parent " $n=2$ " structure, cleaved already along the $<100>$ plane, is further cleaved along the $\left\langle 110>\right.$ plane, giving the general formula $(\mathrm{PA})_{2 \mathrm{~m}+4}(\mathrm{MA})_{\mathrm{m}-2} \mathrm{~Pb}_{2 \mathrm{~m}+1} \mathrm{I}_{7 \mathrm{~m}+4}$. These structures have corner-sharing as well as face-sharing $\mathrm{PbI}_{6}$ octahedra, but is distinct from the previously reported $(\mathrm{PA})_{3} \mathrm{~Pb}_{2} \mathrm{I}_{7}$ structure which also has mixed-sharing connectivity. ${ }^{55}$ For $\mathrm{n}>2$ the $\mathrm{RP}$ 
materials are stabilized. For high $\mathrm{m}(\mathrm{m}=4)$, the structure is most like that of the RP structures while $m=2$ deviates significantly because of its increased face-sharing connectivity. Thus, this system allows us to carefully tune the structure and compare it to the RP $n=3$ and $n=4$ structures using the same spacer, giving us the ability to test the effects of connectivity in a logical, controlled manner. The optical properties of the RP materials are blue-shifted relative to $\mathrm{MAPbI}_{3}$, but for the new SL structures, the band gap is further blue-shifted with increasing bandgap from $\mathrm{m}=4$ to 2 , allowing for even further tuning of the bandgap. Band structure calculations show dispersive bands and suggest the SL materials are electronically 1D quantum wires while the RP materials are electronically $2 \mathrm{D}$ quantum wells. The RP materials exhibit a strong photoresponse. Because of the good photoresponse of the RP $n=3$ material, it was employed in photovoltaic devices. By utilizing our previously studied "hotcasting" technique ${ }^{56}$ along with so-called solvent engineering, ${ }^{57}$ a preliminary assessment gave an efficiency of $7.04 \%$ (average of $6.28 \pm 0.65 \%$ ) was obtained with limited hysteresis and practically no current leakage.

\section{Experimental}

\section{Synthesis.}

See Table S1for a summary of synthetic procedures.

$(\mathbf{P A})_{\mathbf{8}} \mathbf{P b}_{\mathbf{5}} \mathbf{I}_{18}(\mathbf{m}=\mathbf{2}) . \mathrm{PbO}(2.232 \mathrm{~g}, 10 \mathrm{mmol})$ was dissolved in a mixture of $10.0 \mathrm{~mL}$ aqueous $\mathrm{HI}$ and $1.7 \mathrm{~mL}$ aqueous $\mathrm{H}_{3} \mathrm{PO}_{2}$ by heating at $190{ }^{\circ} \mathrm{C}$ under constant magnetic stirring for $15 \mathrm{~min}$. In a separate vial, $5 \mathrm{~mL}$ aqueous HI was cooled in an ice bath. Then, PA (1.316 mL, $16 \mathrm{mmol})$ was added slowly and allowed 5 min to fully neutralize. To the hot bright yellow solution was added the neutralized PA. The resulting yellow solution was stirred for $5 \mathrm{~min}$. Then, it was allowed to 
cool to room temperature and recrystallize for $45 \mathrm{~min}$, giving yellow needles. The needles were dried through vacuum filtration for $30 \mathrm{~min}$ before being dried under vacuum overnight. Yield $4.6979 \mathrm{~g}(61.80 \%$ based on mol $\mathrm{Pb})$.

$(\mathbf{P A})_{10}(\mathbf{M A}) \mathbf{P b}_{7} \mathbf{I}_{25}(\mathbf{m}=\mathbf{3}) . \mathrm{PbO}(2.232 \mathrm{~g}, 10 \mathrm{mmol})$ was dissolved in a mixture of $8.0 \mathrm{~mL}$ aqueous $\mathrm{HI}$ and $1.7 \mathrm{~mL}$ aqueous $\mathrm{H}_{3} \mathrm{PO}_{2}$ by heating at $200{ }^{\circ} \mathrm{C}$ under constant magnetic stirring for $15 \mathrm{~min}$. To this was added $\mathrm{MACl}(196.9 \mathrm{mg}, 2.91 \mathrm{mmol})$, which formed a black precipitate which was allowed to redissolve. In a separate vial, $2 \mathrm{~mL}$ aqueous $\mathrm{HI}$ was cooled in an ice bath. Then, PA (1.028 mL, $12.51 \mathrm{mmol})$ was added slowly and allowed at least 5 min to fully neutralize. To the hot bright yellow solution was added the neutralized PA. The resulting yellow solution was stirred until it began to boil. Then, it was allowed to cool to room temperature and recrystallize overnight, giving orange needles. The plates were dried through vacuum filtration for $30 \mathrm{~min}$ before being dried under vacuum overnight. XRD shows a mixture of $\mathrm{m}=2, \mathrm{~m}=3$, and a minor phase, $(\mathrm{PA})_{3} \mathrm{~Pb}_{2} \mathrm{I}_{7}$.

$(\mathbf{P A})_{12}(\mathbf{M A})_{2} \mathbf{P b}_{\mathbf{9}} \mathbf{I}_{\mathbf{3 2}}(\mathbf{m}=\mathbf{4}) . \mathrm{PbO}(2.232 \mathrm{~g}, 10 \mathrm{mmol})$ was dissolved in a mixture of $10.0 \mathrm{~mL}$ aqueous $\mathrm{HI}$ and $1.7 \mathrm{~mL}$ aqueous $\mathrm{H}_{3} \mathrm{PO}_{2}$ by heating at $200{ }^{\circ} \mathrm{C}$ under constant magnetic stirring for $15 \mathrm{~min}$. To this was added $\mathrm{MACl}(338 \mathrm{mg}, 5 \mathrm{mmol})$, which formed a black precipitate which was allowed to redissolve. In a separate vial, $2 \mathrm{~mL}$ aqueous $\mathrm{HI}$ was cooled in an ice bath. Then, PA $(822 \mu \mathrm{L}, 10 \mathrm{mmol})$ was added slowly and allowed at least $5 \mathrm{~min}$ to fully neutralize. To the hot bright yellow solution was added the neutralized PA. The resulting yellow solution was stirred until it began to boil. Then, it was allowed to cool to room temperature and recrystallize overnight, giving red elongated plates. The plates were dried through vacuum filtration for 30 min before being dried under vacuum overnight. Yield $1.8494 \mathrm{~g}(24.81 \%$ based on total $\mathrm{Pb})$. 
$(\mathbf{P A})_{2}(\mathbf{M A})_{2} \mathbf{P b}_{\mathbf{3}} \mathbf{I}_{10}(\mathbf{n}=\mathbf{3}) . \mathrm{PbO}(2.232 \mathrm{~g}, 10 \mathrm{mmol})$ was dissolved in a mixture of $10.0 \mathrm{~mL}$ aqueous $\mathrm{HI}$ and $1.7 \mathrm{~mL}$ aqueous $\mathrm{H}_{3} \mathrm{PO}_{2}$ by heating at $190{ }^{\circ} \mathrm{C}$ under constant magnetic stirring for $15 \mathrm{~min}$. To this was added $\mathrm{MACl}(450 \mathrm{mg}, 6.67 \mathrm{mmol})$, which formed a black precipitate which was allowed to redissolve. In a separate vial, $5 \mathrm{~mL}$ aqueous $\mathrm{HI}$ was cooled in an ice bath. Then, PA (548 $\mu \mathrm{L}, 6.67 \mathrm{mmol})$ was added slowly and allowed at least $5 \mathrm{~min}$ to fully neutralize. To the hot bright yellow solution was added the neutralized PA. The resulting yellow solution was stirred for $5 \mathrm{~min}$. Then, it was allowed to cool to room temperature and recrystallize for $1.5 \mathrm{hr}$, giving dark red plates. The plates were dried through vacuum filtration for $30 \mathrm{~min}$ before being dried under vacuum overnight. Yield $2.4019 \mathrm{~g}(34.73 \%$ based on total $\mathrm{Pb})$.

$(\mathbf{P A})_{2}(\mathbf{M A})_{3} \mathbf{P b}_{\mathbf{4}} \mathbf{I}_{13}(\mathbf{n}=\mathbf{4}) . \mathrm{PbO}(2.232 \mathrm{~g}, 10 \mathrm{mmol})$ was dissolved in a mixture of $10.0 \mathrm{~mL}$ aqueous $\mathrm{HI}$ and $1.7 \mathrm{~mL}$ aqueous $\mathrm{H}_{3} \mathrm{PO}_{2}$ by heating at $190{ }^{\circ} \mathrm{C}$ under constant magnetic stirring for $15 \mathrm{~min}$. To this was added $\mathrm{MACl}(507 \mathrm{mg}, 7.5 \mathrm{mmol})$, which formed a black precipitate which was allowed to redissolve. In a separate vial, $3 \mathrm{~mL}$ aqueous $\mathrm{HI}$ was cooled in an ice bath. Then, PA $(411 \mu \mathrm{L}, 5.0 \mathrm{mmol})$ was added slowly and allowed at least $5 \mathrm{~min}$ to fully neutralize. To the hot bright yellow solution was added the neutralized PA. The resulting yellow solution was stirred for $5 \mathrm{~min}$. Then, it was allowed to cool to room temperature and recrystallize for $1.5 \mathrm{hr}$, giving black plates. The plates were dried through vacuum filtration for 30 min before being dried under vacuum overnight. XRD shows some impurities such as $\mathrm{n}=3$ and $\mathrm{MAPbI}_{3}$. Yield $1.4588 \mathrm{~g}(21.70 \%$ based on total $\mathrm{Pb})$.

\section{Materials Characterization}

High resolution synchrotron powder X-ray diffraction (SXRD) data were collected at beamline 11-BM-B of the Advanced Photon Source (APS), Argonne National Laboratory using 
$\lambda=0.412736 \AA$. Discrete detectors covering an angular range from -4 to $2^{\circ} 2 \theta$ were scanned over a $26^{\circ} 2 \theta$ range, with data points collected every $0.001^{\circ} 2 \theta$ and a scan speed of $0.1^{\circ} / \mathrm{s}$.

Single-crystal X-ray diffraction experiments were performed using a STOE IPDS II or IPDS 2T diffractometer with Mo K $\alpha$ radiation $(\lambda=0.71073 \AA)$ and operating at $50 \mathrm{kV}$ and 40 $\mathrm{mA}$. Integration and numerical absorption corrections were performed using the X-AREA, XRED, and X-SHAPE programs. The structures were solved by charge flipping and refined by full-matrix least-squares on F2 using the Jana2006 package. ${ }^{58}$ The PLATON ${ }^{59}$ software was used to identify the twinning domains and validate the space groups of the compounds.

A Shimadzu UV-3600 PC double-beam, double-monochromator spectrophotometer was used to acquire room-temperature optical diffuse reflectance spectra of the powdered samples in the range of $200-2500 \mathrm{~nm}$. $\mathrm{BaSO}_{4}$ was used as a non-absorbing reflectance reference, and reflectance data were converted to absorbance data via Kubelka-Munk transformation. Both bandgaps and exciton energies were extracted from the data. The exciton energies were estimated based on the position of the exciton peak residing below the bandgap. The linear portion of the curve above the exciton was used to extract the bandgap based on its intersection with the x-axis. Low-energy impurity peaks, appearing as tails in the spectra, were ignored.

First-principles calculations are based on density functional theory (DFT) as implemented in the SIESTA package. ${ }^{60-61}$ Calculations have been carried out on experimental structures with the GGA functional in the revPBE form. ${ }^{62}$ Core electrons are described with Troullier-Martins pseudopotentials. ${ }^{63}$ The valence wavefunctions are developed over double- $\zeta$ polarized basis set of finite-range numerical pseudoatomic orbitals. ${ }^{64}$ In our calculations, spin-orbit coupling is taken into account through the on-site approximation as proposed by Fernández-Seivane et al. ${ }^{65}$ In all cases, an energy cutoff of 150 Ry for real-space mesh size has been used. 
Current-voltage (I-V) curves were measured at room temperature in air using a Keithley $6517 \mathrm{~b}$ picoammeter/voltage supply under -10 to $10 \mathrm{~V}$ bias via a two-probe method. Devices were made using single crystals of the compounds. Electrical contacts were applied through 100 $\mu \mathrm{m}$ copper wires adhered to the crystal specimens through colloidal graphite paste.

Measurements were made on single crystals with a specific direction chosen based on the faces of the crystals and correlated using BFDH morphology simulations by the Mercury software. ${ }^{66}$ The devices were put inside a guarded dark box for dark measurements. Additionally, they were measured under a white light source with a power setting of $7 \mathrm{~W}$ (Taotronics TT-DL11).

Resistivity was calculated using the equation $\rho=R * \frac{A}{l}$ where $\rho$ is resistivity, $R$ is resistance calculated by the slope of the I-V curve collected above, and $A$ and $l$ are the cross-sectional area of the crystal and the length from one contact to the other. It was assumed that the contact resistance was similar for each crystal.

\section{Thin Film Characterization}

Thin films were prepared on glass substrates. XRD measurements were carried out on a Rigaku MiniFlex600 X-ray diffractometer ( $\mathrm{Cu}$ Ka radiation, $\lambda=1.5406 \AA$ ) operating at $40 \mathrm{kV}$ and $15 \mathrm{~mA}$. GIWAXS measurements were performed at Beamline 8-ID-E of the Advanced Photon Source at Argonne National Laboratory. Samples prepared on glass substrates were exposed to an X-ray beam $(\lambda=1.6868 \AA)$ at an incident angle of $0.15^{\circ}$ for $1 \mathrm{~s}$, and the scattered light was collected by a Pilatus $1 \mathrm{M}$ pixel array detector at $204 \mathrm{~mm}$ from the sample. The GIXSGUI program was used to plot images of the patterns. ${ }^{67}$

\section{Solar Cell Device Fabrication}

The ITO-coated glass substrates (TEC7, $2.2 \mathrm{~mm}$, Hartford Glass Co. Inc.) were cleaned by sequential sonication in aqueous detergent, deionized water, acetone, and isopropyl alcohol 
for 10 min each, followed by a 3 min oxygen plasma treatment. A thin layer of PEDOT:PSS was deposited on the precleaned ITO substrates by spin-coating at $6000 \mathrm{rpm}$ for $30 \mathrm{~s}$ and annealed at $150{ }^{\circ} \mathrm{C}$ for $30 \mathrm{~min}$ in air. The substrates were then transferred to an argon-filled glovebox to complete the rest of the device fabrication. Solutions of $(\mathrm{PA})_{2}(\mathrm{MA})_{2} \mathrm{~Pb}_{3} \mathrm{I}_{10}$ were prepared by dissolving $60 \mathrm{mg}$ of the oven-dried crystals in $100 \mu \mathrm{L}$ of DMF and $300 \mu \mathrm{L}$ of DMSO solvents. Different volumes of DMSO were incorporated into the total $400 \mu \mathrm{L}$ when optimizing solvent choice $(0,100,200,300$, and 4000$)$. The perovskite layer was deposited by hot-casting $75 \mu \mathrm{L}$ of the as-prepared room-temperature solution on the ITO/PEDOT:PSS substrates heated to $110^{\circ} \mathrm{C}$ for $20 \mathrm{~s}$ at $5000 \mathrm{rpm}$. Within 6-7 s of spin coating, the films turned from yellow to brown. The $\mathrm{PC}_{61} \mathrm{BM}$ (Sigma Aldrich) layer was deposited on the perovskite film from a $30 \mathrm{mg} / \mathrm{mL} \mathrm{PC}{ }_{61} \mathrm{BM}$ solution in CB at $1000 \mathrm{rpm}$ for $30 \mathrm{~s}$. Finally, $100 \mathrm{~nm}$ of Al was thermally evaporated through a shadow mask at a pressure of $\sim 1 \times 10^{-6}$ Torr. Half of the area was encapsulated by epoxy (Epoxy Technology) and UV-cured for $30 \mathrm{~min}$. The active area of the device was $0.03 \mathrm{~cm}^{2}$.

\section{Solar Cell Device Characterization}

The current density versus voltage $(\mathrm{J}-\mathrm{V})$ characteristics were collected in air using a Keithley 2400 source meter under simulated AM $1.5 \mathrm{G}$ irradiation $\left(100 \mathrm{~mW} / \mathrm{cm}^{2}\right)$ generated by a standard solar simulator (Abet Technologies). The light intensity was calibrated by using an NREL-certified monocrystalline Si reference cell to reduce the spectral mismatch.

Stability characterization was performed on a device using $75 \%$ DMSO for the precursor solvent. The device was made with the same architecture used previously and encapsulated with the same method. The device was then held under 1 solar sun and measured periodically.

\section{Results and Discussion}




\section{Materials Synthesis}

The materials were synthesized by first dissolving lead oxide $(\mathrm{PbO})$ and methylammonium chloride (MACl) in boiling hydroiodic acid (HI) and hydrophosphorous acid $\left(\mathrm{H}_{3} \mathrm{PO}_{2}\right)$. Then, propylamine (PA), neutralized by $\mathrm{HI}$, was added to the solution. The reagents were originally added in ratios corresponding to the stoichiometry for RP perovskites for different $n$ values using the general formula $\left(A^{\prime}\right)_{2} A_{n-1} M_{n} X_{3 n+1}$. Because of the high solubility of the products, concentrations were kept as high as possible $(\geq 1 \mathrm{M})$. Once dissolved, the solutions were cooled to room temperature by removing the solutions from the hot plate, leading to the precipitation of the materials within minutes. Note that the crystals must be completely dried within hours of precipitation because they can undergo a high rate of disproportionation. As seen in Figure $\mathrm{S} 2$, over days, other $\mathrm{n}$ values began to appear in the PXRD for $(\mathrm{PA})_{2}(\mathrm{MA})_{2} \mathrm{~Pb}_{3} \mathrm{I}_{10}(\mathrm{n}=$ 3), and even within hours, a red tint, indicative of lower $n$ structures, was seen on the edges of the crystals. For $n=3$ and $(\mathrm{PA})_{2}(\mathrm{MA})_{3} \mathrm{~Pb}_{4} \mathrm{I}_{13}(\mathrm{n}=4)$, plates colored dark red and black, respectively, precipitated within minutes (Figure 1). For $n=4$, however, it was fairly common to have impurities of other $n$ members while $n=3$ was more likely to be pure. For $n<3$, needles formed instead of plates. For the experimentally stoichiometric " $(\mathrm{PA})_{2}(\mathrm{MA}) \mathrm{Pb}_{2} \mathrm{I}_{7}$ " samples, red flat needles formed instead and for " $(\mathrm{PA})_{2} \mathrm{PbI}_{4}$ " yellow needles formed. The "( $\left.\mathrm{PA}\right)_{2} \mathrm{PbI}_{4}$ " sample matched the calculated PXRD for a previously reported material by Billing and Lemmerer, $(\mathrm{PA})_{8} \mathrm{~Pb}_{5} \mathrm{I}_{18},{ }^{68}$ but the " $(\mathrm{PA})_{2}(\mathrm{MA}) \mathrm{Pb}_{2} \mathrm{I}_{7}$ " material did not match any known phase. After resolving the crystal structure for this material, it was revealed that the so-called " $(\mathrm{PA})_{2} \mathrm{PbI} \mathrm{I}_{4}$ " and “(PA $)_{2}(\mathrm{MA}) \mathrm{Pb}_{2} \mathrm{I}_{7}$ " materials were part of a homologous series of SL materials with the general formula $(\mathrm{PA})_{2 \mathrm{~m}+4}(\mathrm{MA})_{\mathrm{m}-2} \mathrm{~Pb}_{2 \mathrm{~m}+1} \mathrm{I}_{7 \mathrm{~m}+4}$. 
To further probe this series for new phases, syntheses were performed using stoichiometric ratios for values of $\mathrm{m}$ from 2 to 4 . Unexpectedly, doing so led to the precipitation of the yellow $(\mathrm{PA})_{8} \mathrm{~Pb}_{5} \mathrm{I}_{18}(\mathrm{~m}=2)(\mathrm{Pb}: \mathrm{I}$ is 1:3.60) phase in all cases. Using the stoichiometry for “( $\mathrm{PA})_{2}(\mathrm{MA}) \mathrm{Pb}_{2} \mathrm{I}_{7}$ " $(\mathrm{Pb}: \mathrm{I}$ is 1:3.50) was the most reliable way to precipitate the red

$(\mathrm{PA})_{12}(\mathrm{MA})_{2} \mathrm{~Pb}_{9} \mathrm{I}_{32}(\mathrm{~m}=4, \mathrm{~Pb}: \mathrm{I}$ is 1:3.56). When using an intermediate ratio of reagents between the stoichiometry for " $\left(\mathrm{PA}_{3}\right)_{2}(\mathrm{MA}) \mathrm{Pb}_{2} \mathrm{I}_{7}$ " and $(\mathrm{PA})_{12}(\mathrm{MA})_{2} \mathrm{~Pb}_{9} \mathrm{I}_{32}$, a mixture of three phases formed: yellow needles identified as $\mathrm{m}=2$, orange needles identified as $(\mathrm{PA})_{11}(\mathrm{MA}) \mathrm{Pb}_{7} \mathrm{I}_{25}(\mathrm{~m}=$ 3, $\mathrm{Pb}: \mathrm{I}$ is 1:3.57), and white needles identified as the MA-free $(\mathrm{PA})_{3} \mathrm{~Pb}_{2} \mathrm{I}_{7}$. The third phase was an impurity, though it was previously reported as the primary product under synthetic conditions similar to those used here to synthesize $\mathrm{m}=2 .{ }^{55}$ No instances of $\mathrm{m}>4$ were seen as the stoichiometry further approached that of " $(\mathrm{PA})_{2}(\mathrm{MA}) \mathrm{Pb}_{2} \mathrm{I}_{7}$ ". Furthermore, using limiting or excess of a single reagent simply led to mixtures of the title phases and no new phases were detected.

The SL $(\mathrm{PA})_{2 \mathrm{~m}+4}(\mathrm{MA})_{\mathrm{m}-2} \mathrm{~Pb}_{2 \mathrm{~m}+1} \mathrm{I}_{7 \mathrm{~m}+4}$ materials are derived from the hypothetical RP " $\mathrm{n}=$ 2 " structure. In this case, when $\mathrm{m}=\infty$, the formula collapses to $(\mathrm{PA})_{2}(\mathrm{MA}) \mathrm{Pb}_{2} \mathrm{I}_{7}$, which is the equivalent to the RP (PA) $2(M A)_{n-1} \mathrm{~Pb}_{n} \mathrm{I}_{3 n+1}$ " $\mathrm{n}=2$ " member. All the SL structures begin to deviate from the RP series because of an increasing ratio of $\mathrm{PA}^{+}: \mathrm{MA}^{+}$from $2: 1$ for " $\mathrm{n}=2$ " to infinity for $\mathrm{m}=2$ and a slightly decreasing ratio of $\mathrm{Pb}$ :I from 1:3.5 to 1:3.6.

\section{Description of Crystal Structures.}

Step-like Structures. Using propylammonium as a spacer results in a SL structures instead of the expected " $n=1$ " and " $n=2$ " RP homologous members. The SL structures involve both cornersharing and face-sharing $\mathrm{PbI}_{6}$ octahedra, which have been colored blue and pink, respectively, in 
Figure 2. These compounds form their own homologous series within the " $n=2$ " window, which are described by the general formula $(\mathrm{PA})_{2 \mathrm{~m}+4}(\mathrm{MA})_{\mathrm{m}-2} \mathrm{~Pb}_{2 \mathrm{~m}+1} \mathrm{I}_{7 \mathrm{~m}+4}(\mathrm{~m} \geq 2)$. Having identified this new homology here we can see that the previously reported $\mathrm{m}=2$ compound $^{68}$ is a member along with the $\mathrm{m}=3$ and 4 compounds reported here for the first time. Each of these structures, like the RP perovskites, can be imagined as a derivative of a parent structure. For the RP perovskites, the parent structure is $\mathrm{MAPbI}_{3}$, which has been cleaved along the $<100>$ plane by the stoichiometric addition of the iodide salts of the alkylammonium cations. For the SL structures, however, the parent structure is the hypothetical " $n=2$ " RP structure which, as mentioned earlier, is essentially $\mathrm{MAPbI}_{3}$ cleaved along the $<100>$ plane. The SL structure can then be imagined to be cleaved a second time along the $<110>$ plane of $\mathrm{MAPbI}_{3}$, which is described by the $\mathrm{m}$ variable in the formula $(\mathrm{PA})_{2 \mathrm{~m}+4}(\mathrm{MA})_{\mathrm{m}-2} \mathrm{~Pb}_{2 \mathrm{~m}+1} \mathrm{I}_{7 \mathrm{~m}+4}$. The combination of these two perpendicular cleaving events produces a $1 \mathrm{D}$ chain of $\mathrm{PbI}_{6}$ octahedra with thickness $\mathrm{n}$, which always equals 2 , and a width of $m$, which varies between 2-4. The use of $m$ is based on the nomenclature previously reported for 2D corner-sharing perovskite structures cleaved along $<110>$. 69

Looking down the monoclinic $\mathrm{b}$ axis shows a cross section of the $1 \mathrm{D}$ chains for $\mathrm{m}=2$, seen as the blue corner-sharing octahedra in Figure 2. In the case of $\mathrm{m}=2$, the chains are $2 \times 2$ octahedra. The $1 \mathrm{D}$ chain for this series is approximately two $\mathrm{PbI}_{6}$ octahedra thick $(\sim 12.5 \AA)$ or $2 \mathrm{a}^{\prime}$ in length, (where $\mathrm{a}^{\prime}$ is the ideal cubic perovskite lattice constant) corresponding to $\mathrm{n}=2$ thickness. The width for $\mathrm{m}=2,3$, and 4 is $9.1351 \AA\left(2 \mathrm{a}^{\prime} / \sqrt{ } 2\right), 13.7718 \AA\left(3 \mathrm{a}^{\prime} / \sqrt{ } 2\right)$, and $18.1148 \AA$ $\left(4 a^{\prime} / \sqrt{ } 2\right)$, respectively. Looking down the c axis in Figure $3 b$ gives a side view of the chains, which extend infinitely along the $\mathrm{b}$ axis. As $\mathrm{m}$ increases from 2 to 4 , the pure zigzag connectivity subsides as the chain gains more octahedra and the 1D chains begin to more closely resemble a 
perovskite-like structure. The zigzag connectivity is like that of the $<110>$-oriented $2 \mathrm{D}$ perovskites with proper corner-sharing connectivity as in $\mathrm{m}=2\left[\mathrm{NH}_{2} \mathrm{C}(\mathrm{I})=\mathrm{NH}_{2}\right]_{2} \mathrm{Sn}_{2} \mathrm{I}_{8} \cdot{ }^{39}$

The 1D chains in the SL structures are connected by a single face-sharing octahedron, for which the face-sharing connectivity is at the two opposite corners of these rectangles along the 1D chain. This forms the so-called "steps," as the rectangles are the flat portion of the steps and the face-sharing octahedra are the raise in height for each step. In (PA $)_{2 \mathrm{~m}+4}(\mathrm{MA})_{\mathrm{m}-2} \mathrm{~Pb}_{2 \mathrm{~m}+1} \mathrm{I}_{7 \mathrm{~m}+4}$ the face-sharing octahedra face a different direction than the corner-sharing octahedra with an interval of one octahedron. The few examples of mixed-connectivity structures seen in the halide perovskite literature have also seen different patterns within the context of SL structures. Kamminga et. al. describe a phenylbutylammonium-based material with $\mathrm{n}=1$ and $\mathrm{m}=3$ which is quite similar to the structures reported here. ${ }^{49}$ Interestingly, the shorter chain phenylpropylammonium forms a new type of structure with $\mathrm{n}=1$ and $\mathrm{m}=4$, but with the facesharing octahedra at corners on the same side of the rectangle cross-section, forming a cisorientation. Using a different synthesis, Billing et. al. solved the structure with a phenylpropylammonium spacer with $n=1$ and $m=2$, but this structure has chains of three facesharing octahedra which also arrange in a cis pattern. ${ }^{70}$ Additionally, an all-inorganic structure was reported in for a $\mathrm{SnI}_{6}$ system using a mixture of $\mathrm{Rb}^{+}$and $\mathrm{Cs}^{+} .{ }^{71}$ This appears to be the only other known multilayered structure with mixed-sharing connectivity.

In this homology the $\mathrm{MA}^{+}$always is located within the cages of $2 \times 2 \times 2$ corner-sharing $\mathrm{PbI}_{6}$ octahedra. To form cages, the width of the chains must be at least $\mathrm{m}=3$. With each additional layer, another $\mathrm{MA}^{+}$can be incorporated. For $<100>$-oriented structures in general, the spacing amines align themselves in the interlayer space with the amine group facing the inorganic layers and positioned between the four terminal iodide atoms of four different 
octahedra. For the general $<110>$-oriented structure, the spacing cations orient themselves in a similar manner, but the four octahedra have their edges facing the interlayer space. In the case of the SL structures, the $\mathrm{PA}^{+}$orient themselves at both the $<100>$ and $<110>$ cleavage of the 1D chains. There are $2 \mathrm{~m} \mathrm{PA}^{+}$along the $<100>$ cleavage and 2 along the $<110>$ cleavage, giving $2 \mathrm{~m}$ $+2 \mathrm{PA}^{+}$oriented toward the inorganic chain and 2 still unaccounted. These $2 \mathrm{PA}^{+}$are found in the large space near the face-sharing octahedra. This large space exists because the SL structure of the inorganic layers is suboptimal to pack tightly together. The intermediate size of the $\mathrm{PA}^{+}$ cations allows them to properly fill up the interlayer spacing. If the cation size were smaller, they may be able to incorporate into the $3 \mathrm{D}$ structure in a similar way to $\mathrm{MA}^{+}$. Conversely, if the size was a bit larger or just longer such as $\mathrm{BA}^{+}$, the interlayer spacing would be too small for all the cations to fit and the structure would be destabilized.

When attempting to synthesize the $\mathrm{m}=3$ and 4 structures, a minor phase $(\mathrm{PA})_{3} \mathrm{~Pb}_{2} \mathrm{I}_{7}$ forms as well (Figure S3). ${ }^{55}$ The structure has also mixed face- and corner-sharing motifs with $1 \mathrm{D}$ chains of corner-sharing octahedra cut along the $<100>$ and $<110>$ axes, and there is no fully face-sharing octahedron, causing the chains to be at alternating orientations to one another. The $(\mathrm{PA})_{3} \mathrm{~Pb}_{2} \mathrm{I}_{7}$ however was only made as an impurity and its study is out of the scope of this paper, so the characterization is not reported here beyond the crystallographic data given in Table 1.

Ruddlesden-Popper Structures. The $\mathrm{n}=3$ and $\mathrm{n}=4$ structures can be classified as RuddlesdenPopper (RP) materials. Like other RP systems, the $n=3$ and $n=4$ structures are fully cornersharing structures belonging to the formula $(\mathrm{PA})_{2}(\mathrm{MA})_{\mathrm{n}-1} \mathrm{~Pb}_{\mathrm{n}} \mathrm{I}_{3 \mathrm{n}+1}$ but with a considerably contracted stacking repeat length given the short spacer (Figure 3). Crystallographic data is reported in Table 1 and selected bond distances, angles, etc. in Tables S2-16. Like other RP 
structures, the structures can be imagined as $\mathrm{MAPbI}_{3}$ cleaved along the $<100>$ plane by spacing cations, which in this case $\mathrm{A}^{\prime}$ is propylammonium. The $\mathrm{PbI}_{6}$ octahedra, both terminal and within the layers, experience distortion along all three axes, with the $\mathrm{Pb}-\mathrm{I}-\mathrm{Pb}$ angles ranging from $161.77^{\circ}$ to $171.28^{\circ}$, similar to other alkylamine-based perovskites. ${ }^{13}$ The $n=3$ structure crystallizes in the monoclinic space group $P 2_{1} / a$, as opposed to the $\mathrm{n}=3 \mathrm{BA}$ compounds which crystallize in the orthorhombic space group $C 2 c b$ and $n=3$ PEA compound which crystallize in the triclinic space group $P 1$. The decrease in symmetry for PA $n=3$ is caused by the unique alignment of the layers in the structure. In general, RP perovskites have layers shifted by half an octahedral unit length in the layer plane $((1 / 2,1 / 2)$ displacement $)$ so that when looking perpendicular to the layers, the successive layers alternate in position (Figure 3). In the case of the PA system, however, as the layers are brought together in closer proximity, they are not fully shifted and the displacement is closer to $(1 / 4,1 / 4)$, lying in between the stacking sequences of RP and DJ perovskites. A change in the stacking sequence may also occur as a function of temperature for layered perovskites such as $\left(\mathrm{C}_{5} \mathrm{H}_{11} \mathrm{NH}_{3}\right)_{2} \mathrm{PbI}_{4} \cdot{ }^{72}$ Different layer alignments are common in 2D halide perovskites when small spacer cations are employed, as seen in the case of $\mathrm{GA},{ }^{29-30}$ in which the layers are $(1 / 2,0)$ (the ACI perovskite), and for hybrid $\mathrm{DJ}^{28}$ perovskites, in which the layers have no shift (Figure 3c,d). In addition, in the monoclinic setting, the unit cell no longer doubles but instead incorporates only one layer. A similar primitive monoclinic unit cell without cell doubling along the stacking axis was also identified for ([p$\left.\mathrm{FC}_{6} \mathrm{H}_{5} \mathrm{C}_{2} \mathrm{H}_{4} \mathrm{NH}_{3}\right]_{2} \mathrm{PbI}_{4}$ ). The reduced point symmetry of the lattice by comparison to RP, DJ, and ACI structures is compensated by the smaller number of atoms in the unit cell. ${ }^{73-74}$ Finally, the intermediate-sized propylammonium spacer also results in a relatively short interlayer spacing of 


\author{
$6.03 \AA$, which is shorter than the width of $\mathrm{a} \mathrm{PbI}_{6}$ in the structure $(\sim 6.3 \AA)$ and an I-I distance of \\ only $6.75 \AA$.
}

\title{
Optical Properties
}

Optical Absorption. Freshly dried crystals were used to acquire the optical responses of these materials. ${ }^{75}$ Diffuse reflectance of the bulk polycrystalline powders obtained at room temperature were used to create Kubelka-Munk plots for bandgap determination (Figure 4a). Note that the spectra here contain two features: a bandgap absorption and an excitonic peak at a lower energy. The bandgap was then estimated by the intercept of the linear portion of the spectra with the x-axis, considering only the portion of the spectrum at higher energy than the excitonic peak. Note that strong impurity peaks, likely $n=1,2$, or 3 , which may have formed on the surfaces of the crystals for the SL structures, are seen as tails toward the low energy end of the spectra. Despite not being able to make the $n=1$ and $n=2$ RP structures in bulk, they may be stabilized at the surfaces of the SL compounds, which would influence the optical spectrum. The exciton energy, when possible, was also estimated based on position of the low-energy exciton peak. It should also be noted that the absorption edge extends well beyond the bandgap, as has been seen in previous reports which seemed to depend on the preparation method, in particular when using HI during the synthesis. ${ }^{31,76}$

The SL materials show higher bandgap compared to other RP $\mathrm{n}=2$ materials, ${ }^{41}$ which reflects the decrease in structural dimensionality, as the perovskite-like connectivity only extends in one dimension, even though the compound remains 2D structurally. Within the homologous series of SL materials, the bandgap increases as $m$ decreases, showing that the width of the quantum wire (and thus its cross-sectional area) plays a key role in the quantum confinement. As 
$\mathrm{m}$ decreases from 4 to 3 to 2 , the bandgap increases from $2.53 \mathrm{eV}$ to $2.74 \mathrm{eV}$ to $2.93 \mathrm{eV}$, indicating a further increase in the electronic confinement with decreasing cross-sectional area. Interestingly, the $\mathrm{m}=2$ structure has a bandgap closer to that of the $<110>$-oriented GA $m=2$ structure $(2.49 \mathrm{eV})$ rather than to $\mathrm{BA} \mathrm{n}=2(2.17 \mathrm{eV}),{ }^{77}$ revealing a strong structural correlation between the $<110>$-oriented GA and a marked difference with the $<100>$-oriented BA, despite both orientations being present in PA.

As expected, in comparison to the $\mathrm{MAPbI}_{3}$ bandgap $(1.52 \mathrm{eV})$, the $\mathrm{n}=4$ and $\mathrm{n}=3$

materials were blue-shifted with bandgaps of $1.90 \mathrm{eV}$ and $2.03 \mathrm{eV}$, respectively. This is because of increasing quantum and dielectric confinement in the $\mathrm{z}$ direction with progressively thinner perovskite layers. The same trend can be seen from the excitonic peaks, with energies of $1.86 \mathrm{eV}$ and $2.00 \mathrm{eV}$.

Photoluminescence (PL). The PL of crystals of the different materials were measured at room temperature (Figure 4b). The SL structures are again blue-shifted compared to the RP structures and continue to blue shift with decreasing $\mathrm{m}$. Similar to the optical absorption, $\mathrm{n}=3$ and $\mathrm{n}=4$ were shown to blue shift with decreasing layer thickness. A comparison of the bandgaps and PL is shown in Figure 4c. A notable difference between the RP and SL structure is the intensity of the PL peaks, with RP perovskites showing a strong narrow emission and the SL perovskites exhibiting a weak emission. PL lifetime measurements show that the average lifetime decreases from $3.10 \mathrm{~ns}$ to $2.37 \mathrm{~ns}$ to $0.29 \mathrm{~ns}$ from $\mathrm{m}=4$ to 3 to 2 (Figure $\mathrm{S} 4$ ). The short lifetimes suggest that efficient non-radiative decay routes are significant in these materials, dominating that of the radiative processes. Based on DFT calculations in the next section, it appears that these materials have indirect bandgaps, suggesting that the PL is a result of a trap-assisted process not directly produced from the bandgap, leading to weak emissions. This hypothesis is also consistent with 
the broadening of the PL peaks down to $1.8 \mathrm{eV}$, as a broad number of states beyond the bandgap can participate in these processes.

\section{Electronic Properties.}

DFT electronic structure calculations were performed on each of these materials (Figure 5). The SL materials have different electronic structure with significantly less dispersive bands than RP materials. Using the $\mathrm{m}=2$ member as an example, the bands show some dispersion parallel to the $1 \mathrm{D}$ chains of corner-sharing $\mathrm{PbI}_{6}$ octahedra, though less so compared to the RP phases. This is because the $1 \mathrm{D}$ corner-sharing chains are similar to the corner-sharing in the RP perovskite derivatives, while the face-sharing connections in the structure along the layer seem to weaken the hybridization of electronic atomic states close to the bandgap. This can be most readily visualized by the partial charge densities computed at the VBM and CBM in Figure 5, where both the intralayer face-sharing and the interlayer directions lead to a localization of the electron densities. As seen by the VBM of $\mathrm{m}=2$, the face-sharing octahedra have negligible electron density, as the main fraction of the electron density localized on the corner-sharing octahedra. Based on this result, we can conclude that the face-sharing octahedra affect the electronic dimensionality of the perovskite-like corner-sharing 1D chains, acting as electronic barrier, a conclusion which agrees well with previous reports of structures with face-sharing connectivity. ${ }^{53}$ Furthermore, the third direction, running parallel to the chains of corner-sharing octahedra, has little dispersion compared to the calculations for $\mathrm{n}=3$, indicating the zigzag connectivity also leads to poor dispersion. This is consistent with other $<100>$-oriented layered halide perovskites, such as ammonium-propyl-imidazole-based structures. ${ }^{78}$ As $\mathrm{m}$ increases, the dispersion along the chains of corner-sharing octahedra increases, as expected because of the 
increased perovskite-like character of the chains. Furthermore, the $m=4$ structure begins to show small amounts of coupling between the chains, overcoming the face-sharing octahedra barrier. The local density of states close to the band edges also becomes similar to that of RP structures.

For the $\mathrm{n}=3$ and $\mathrm{n}=4 \mathrm{RP}$ materials, the band structure show an almost direct bandgap similar to that of the other RP materials. ${ }^{41}$ The calculations indicate that the $\mathrm{n}=3$ member is a direct bandgap semiconductor at the $\Gamma$ point of the Brillouin zone, whereas the $n=4$ member has a slightly indirect bandgap at the $\Gamma$ point (Figure $5 \mathrm{a}$ ). The $\mathrm{n}=4$ member shows a slight deviation from the typical direct bandgap behavior, observed in halide perovskites because of strong Rashba splitting caused by the noncentrosymmetric nature of its structure. Within the layers, the electronic bands are dispersive because of their perovskite-like nature resulting from the cornersharing $\mathrm{PbI}_{6}$ octahedra. Across the layers in the $\mathrm{z}$ direction, however, the bands show virtually no dispersion because of the structural discontinuity caused by the spacing of the propylammonium cations. As was reported previously, the conduction band maximum (CBM) is made mainly of $6 \mathrm{p}$ orbitals of $\mathrm{Pb}$ located on the top and bottom surface of the perovskite slabs while the valence band maximum (VBM) is made mainly of $5 p$ orbitals of I located in the center, similar to the BA-based RP structures. ${ }^{30}$

It is worth pointing out that $\mathrm{m}=2$ shows a clear indirect bandgap while $\mathrm{m}=3$ and $\mathrm{m}=4$ both show almost direct bandgaps. Even though the calculated bandgap is underestimated, which is common for this type of calculations, ${ }^{41}$ the general experimental trend is captured by the DFT calculations, with the slight exception of $m=3$ (Figure S4). In this case, the calculated bandgaps for the materials are $0.51 \mathrm{eV}$ for $\mathrm{n}=4,1.03 \mathrm{eV}$ for $\mathrm{n}=3,1.75 \mathrm{eV}$ for $\mathrm{m}=4,1.60 \mathrm{eV}$ for $\mathrm{m}=3$, and $2.27 \mathrm{eV}$ for $\mathrm{m}=2$. 


\section{Electrical Properties}

Photoconductivity measurements were taken for $n=3$ RP perovskite, $m=2$, and $m=4$

SL perovskites at room temperature using a two-probe setup. Individual faceted crystals of each compound were measured along different directions with the intention to capture the highly anisotropic properties of the crystals.

For the SL materials, three unique directions are possible. For $\mathrm{m}=2$, the crystals are needles which can be imagined as rectangular prisms elongated along the $b$-axis. From tip-to-tip for these needles, the crystallographic direction is the $b$-axis, which is the axis running parallel to the $1 \mathrm{D}$ chains of corner-sharing octahedra. The measured resistivity is high along this direction ( $\rho \sim 10^{10} \Omega \cdot \mathrm{cm}$ ), but still an order of magnitude smaller than the one corresponding to the crossplane direction in RP phases discussed below, while measurements along the $a$ - and $c$-axes gives resistivities on the order of $\rho \sim 10^{7}-10^{8} \Omega \cdot \mathrm{cm}$. While the resistivity values are seemingly quite low here, it has been noted that ion migration is common in perovskites ${ }^{79-80}$ and increased in $2 \mathrm{D}$ perovskites because of octahedral distortion. ${ }^{81}$ In the SL structures, the octahedral distortions are significant, as in the RP structures. Also, the layers are no longer flat and thus have more exposure to the interlayer space, which could act as a pathway for ion migration. If this is the case, the measurement would be heavily influenced by ion migration instead of electronic conduction and would lead to inflated values. A similar situation occurs for $m=4$, with values of resistivity $\rho \sim 10^{6} \Omega \cdot \mathrm{cm}$ for the b-axis, $\rho \sim 10^{8} \Omega \cdot \mathrm{cm}$ for the a-axis, and $\rho \sim 10^{6} \Omega \cdot \mathrm{cm}$ for the caxis. While these values are only estimates, they demonstrate the anisotropic effects in these crystals. 
The $n=3$ structure crystallizes as thin rectangular plates in the typical morphology for the RP structures. ${ }^{82}$ Measuring along the tetragonal facets, corresponding to the cross-plane direction, a resistivity of $\rho=10^{11} \Omega \cdot \mathrm{cm}$ was obtained, whereas measuring along the thin sides of the crystals, corresponding to the layer plane direction, resulted in a much smaller resistivity of $\rho$ $=10^{8} \Omega \cdot \mathrm{cm}$ (Figure 6a). This vividly illustrates the anisotropic nature of the RP perovskites, and it is also reasonable in the sense that the resistivity of the layer plane is comparable to that observed for the 3D perovskite $\left(\rho=10^{7} \Omega \cdot \mathrm{cm}\right) .{ }^{83}$ This is understandable, as the carriers easily transport through the perovskite-like planes, whereas much higher bias is required to force the charge carriers to jump across adjacent layers. This observation is in agreement with previously asserted measurements, even though the anisotropy is higher in the PA system compared to the GA system, possibly because of the very short interlayer spacing in the ACI perovskites. ${ }^{29}$ The photoconductive response, measured using white light is clear along both measured directions. Parallel to the layers, the resistivity decreased a hundredfold and perpendicular to the layers, it decreased tenfold. Somewhat surprising is the photoresponse perpendicular to the layers, which implies that some small current can vertically cross the layers. This suggests that certain cations are not sufficiently insulating to completely prevent charge transfer across the layers, even if the transfer is minimal.

It is important to note that the SL materials displayed no difference in the current under dark and light conditions, showing a lack of photoresponse in all directions for both structures. This shows that the SL compounds are inappropriate for photovoltaics, yet they may find applications as dielectric gates in halide perovskite optoelectronics because of their tunable resistivity as a function of the $1 \mathrm{D}$ chain thickness. Furthermore, perovskites have seen utility as ferroelectrics and magnets, as well as being utilized for ion exchange and reactivity 
applications. ${ }^{24,84}$ Since little is understood about how hybrid halide perovskitoids can be utilized for these applications, this system may be used as a tunable model to see how a departure from the perovskite structure affects these materials' behavior in these other applications.

\section{Thin Films and Solar Cell Devices}

Thin Films Because of the negligible photoconductivity of the SL materials, only solar cell devices using the RP phases were considered. Because of the lower purity of $n=4, n=3$ was chosen for device fabrication instead. In a previous report, RP phases were successfully made into high-efficiency devices by a process known as hotcasting. ${ }^{85}$ In this process, the substrate is heated (in this case to $110^{\circ} \mathrm{C}$ ) immediately before spin coating begins, which allows for increased grain passivation and more preferable perpendicular orientation of the layers to the substrate. The devices were shown to have high short-circuit current density $\left(\mathrm{J}_{\mathrm{SC}}\right)$ because of increased charge transfer. Furthermore, solvent engineering has been shown to increase the crystallinity of the $2 \mathrm{D}$ materials in the films.${ }^{57}$ This can be done by simply using mixtures of DMF and DMSO as opposed to only using DMF. The DMSO functions to slow the crystallization of the films from 1-2 s to 6-7 $\mathrm{s}$ and thus leads to better crystallinity. To assess better conditions for devices, XRD of films was measured using different concentrations of DMSO in DMF $(0 \%, 25 \%, 50 \%, 75 \%$, and $100 \%)$. As seen by the PXRD in Figure S6a, the FWHM of the (-110) peak decreases immediately upon addition of DMSO but does not further improve with concentrations of DMSO above $25 \%$. DMSO does, however, lead to a decrease in preferred orientation and a disproportionation of phases, seen by the low angle peaks corresponding to $\mathrm{n}=4$ which grow in with increasing concentrations of DMSO. GIWAXS (Figure 7) further backs these trends, though it shows the $n=3$ material as well based on low 
angle peaks. The spots in the GIWAXS spectrum become rounder as DMSO increases, which shows an increase in crystallinity. This data can be further analyzed by taking line-cuts of the 2D spectrum in different directions. By taking the FWHM along the $\mathrm{q}_{\mathrm{z}}$ and $\mathrm{q}_{\mathrm{y}}$ directions, the crystallinity perpendicular to the substrate and parallel to the substrate, respectively, can be distinguished. As seen in Figure S7, the crystallinity along $q_{z}$ does not change in a substantially nor consistent manner, indicating that the grains did not change in size perpendicular to the substrate. In contrast, along $\mathrm{q}_{\mathrm{y}}$, the crystallinity overall increased and is greater compared to along $\mathrm{q}_{\mathrm{z}}$. This suggests that the crystallites in the film are plate-like and lie parallel to the substrate. Furthermore, increasing the concentration of DMSO increases the width of the crystallites while not increasing the depth. Further studies will be needed to understand the mechanism which leads to these trends and the effect of DMSO.

Solar Cells. Encapsulated devices were prepared using an inverted structure: ITO/PEDOT:PSS/Perovskite/PCBM/A1, in which PEDOT:PSS functioned as the holetransporting material (HTM) and PCBM as the electron-transporting material (ETM). By tuning the percent of DMSO in solution, a respectable average device efficiency of $6.28 \pm 0.65 \%$ was found by using $75 \%$ DMSO, much higher than the $3.70 \pm 0.37 \%$ efficiency for pure DMF. Typical device curves are seen in Figure 8b, and the average parameters are seen in Table S32. Furthermore, the average $\mathrm{V}_{\mathrm{OC}}$ decreased slightly from $1.07 \pm 0.06 \mathrm{~V}$ to $1.00 \pm 0.03 \mathrm{~V}$, the average $\mathrm{J}_{\mathrm{SC}}$ increased significantly from $5.33 \pm 0.66 \mathrm{~mA} / \mathrm{cm}^{2}$ to $10.95 \pm 0.57 \mathrm{~mA} / \mathrm{cm}^{2}$, and the FF decreased slightly from $68.6 \pm 4.6 \%$ to $57.0 \pm 3.5 \%$. The increase in $\mathrm{J}_{\mathrm{SC}}$ is attributed to a slower growth rate of the film from DMSO, which leads to better crystallinity, as mentioned above. The decrease in preferred orientation seems to be less essential in this case than the crystallinity. Even so, DMSO has also shown to lead to very large grain size on the order of over 
a micron, which may lead to small gaps between the grains, negatively affecting the $\mathrm{V}_{\mathrm{OC}}$ and FF, as seen here. ${ }^{57}$ The external quantum efficiency (EQE) was also measured for the devices and is shown in Figure 8c with an integrated $\mathrm{J}_{\mathrm{SC}}$ of $9.23 \mathrm{~mA} \mathrm{~cm}^{-2}$ for $75 \%$ DMSO which is slightly lower than the $\mathrm{J}_{\mathrm{SC}}$ of $11.86 \mathrm{~mA} \mathrm{~cm}^{-2}$ based on the $\mathrm{J}-\mathrm{V}$ curve from the same device. Another point of interest is the broadening in the EQE spectrum with addition of DMSO. Even at 25\% DMSO, the curve has broadened significantly at lower wavelength. However, all films show a very broad spectrum, especially at higher wavelength, as seen by the appearance of a shoulder at around 720 $\mathrm{nm}$. This broadening could be attributed to disproportionation in the films, as evidenced by the presence of $n=4$ in the XRD. The broader EQE implies that this disproportionation is potentially advantageous to absorb a broader range of wavelengths of light.

The wide EQE of the films, potentially due to the disproportionation in the films based on $\mathrm{XRD}$, is promising. In fact, the disproportionation of the $\mathrm{n}$ values in the film based on XRD implies that low $\mathrm{n}$ values are also in existence in the film, as has been reported for other systems spectroscopically. ${ }^{86}$ Here, however, the RP $n=1$ and $n=2$ structures are less likely to form than the SL structures, which have no photoresponse and are detrimental to device performance. The fact that the $\mathrm{J}_{\mathrm{SC}}$ was not as high as expected, along with lower FF and $\mathrm{V}_{\mathrm{OC}}$ suggests that the issues arising here derive from the film morphology and presence of SL structures, not the RP n $=3$ material itself. Furthermore, the increase of $\mathrm{J}_{\mathrm{SC}}$ from DMSO additive implies the changes in morphology and makeup alleviate some of the potential issues, suggesting that further tuning of the conditions for film fabrication could lead to higher $\mathrm{J}_{\mathrm{SC}}$. In fact, for films using the GA spacing cation, fine tuning using antisolvent addition has given efficiencies of $14.7 \%$ once the determinantal $(\mathrm{GA})_{2} \mathrm{PbI}_{4}$ impurity was suppressed. Also like the GA structures, the short interlayer space allows for a lower organic volume in the structure and thus a higher volume of 
perovskite character in the structure, which should allow for a high absorption coefficient. Each of these observations implies the potential for greater $\mathrm{J}_{\mathrm{SC}}$ for PA-based devices once optimization takes place. As a preliminary way to analyze these devices and to better understand this system, further device studies were performed.

Series resistance $\left(\mathrm{R}_{\mathrm{S}}\right)$ can be a major limitation for $\mathrm{J}_{\mathrm{SC}}$ and is here estimated by the slope at the open-circuit voltage, where lower slopes resulting from resistive "tails" near the $\mathrm{V}_{\mathrm{OC}}$ lead to increased $\mathrm{R}_{\mathrm{S}}$. For films with only DMF, a high resistivity is seen, likely due to poor interfaces or defects in film morphology such as low crystallinity and poor mosaicity. This can be tamed by the previously mentioned processing techniques of hotcasting and solvent engineering. In fact, by using solvent engineering through mixing DMF and DMSO, the resistive "tail" seen near the open-circuit voltage disappears entirely under high concentrations of DMSO (Figure 9).

Likewise, the series resistance $\left(\mathrm{R}_{\mathrm{SH}}\right)$ is estimated by the slope at the $\mathrm{J}_{\mathrm{SC}}$, where a greater slope shows more shunt pathways. Once again, this is an effect of the film quality, not the material, and is improved substantially by the addition of DMSO, as seen clearly by the dark curves in Figure 9c,f,i.

The final issue tackled in this system was the hysteresis, which is seen both by varying the scan speed and direction. While using pure DMF gave large hysteresis, DMSO addition diminished the hysteresis substantially. Though full optimization of these devices is out of the scope of this paper, they show the potential for further improvements because of the excellent properties of the crystalline materials and the widened EQE curve, allowing for a broader range of the solar spectrum to be absorbed. It should be noted that, despite having similar bandgaps to the BA system and even shorter interlayer spacing, the performance is still far from that of BA..$^{85}$ Based on the above analysis, it appears that the intrinsic properties of the PA materials are not to 
blame, but the film morphology and makeup hinders the performance. Once the optimal conditions of film formation for this material are better understood, higher films made from pure crystals of these materials can be prepared, and the wide spread of $n$ values in the films can be utilized to get high $\mathrm{J}_{\mathrm{SC}}$ and thus improved efficiencies.

\section{Conclusions}

Using the short $\mathrm{PA}^{+}$spacing cation in $\mathrm{PAI} / \mathrm{MAI} / \mathrm{PbI}_{2}$ reactions results in two homologous series of 2D organic-inorganic hybrid lead iodide materials: RP perovskites (PA) $2(M A)_{n-1} \mathrm{~Pb}_{n} \mathrm{I}_{3 n+1}$ $(\mathrm{n}=3$ and 4$)$ and SL perovskitoids $(\mathrm{PA})_{2 \mathrm{~m}+4}(\mathrm{MA})_{\mathrm{m}-2} \mathrm{~Pb}_{2 \mathrm{~m}+7} \mathrm{I}_{7 \mathrm{~m}+4}(\mathrm{~m}=2,3$, and 4$)$. What is quite remarkable is that, by simply changing the PA:MA ratio, this system gives both the electronically 1D SL materials and the electronically 2D RP materials, showing the huge range of electronic and structural tunability within the same series. These trends are not found in the longer n-alkyl ammonium 2D perovskites. Along with GA and MA in the ACI 2D perovskites, PA is among the shortest organic spacers in 2D perovskites. The SL structures in these materials have a new type of connectivity in the lead iodide layers in which chains of corner-sharing $\mathrm{PbI}_{6}$ octahedra are connected by face-sharing octahedra to form structurally 2D SL slabs. Optically, the PA $n=3$ and $n=4$ structures are like other known RP structures with bandgaps for $n=3$ and 4 of $2.03 \mathrm{eV}$ and $1.90 \mathrm{eV}$ while the SL structures have bandgaps over a wider range for $\mathrm{m}=2,3$, and 4 of $2.93 \mathrm{eV}, 2.74 \mathrm{eV}$, and $2.53 \mathrm{eV}$. This shows that the bandgap can be further tuned by adjusting not only the thickness of the slabs $\mathrm{n}$, but also the width $\mathrm{m}$, which could be useful in designing materials with very specific bandgaps without relying on halide mixing which can result in phase segregation. Unlike the RP structures which are electronically $2 \mathrm{D}$, the SL structures are electronically 1D with dispersion along the corner-sharing chains. Even though the 
chains incorporate every component of the $\mathrm{MAPbI}_{3}$ structure for $\mathrm{m}=3$ and 4 , the materials are confined to one dimension, showing the possibility for $2 \mathrm{D}$ perovskite-like materials which are electronically 1D, further enhancing the ability to play with the optical and electronic properties of these materials by simply adjusting the spacing cation.

The RP materials have good charge transport along the lead-iodide slabs along with a good photoresponse, allowing them to be used in solar cells. By using solvent engineering with varying DMF/DMSO mixtures, crystalline films can be made, leading to solar cells with respectable efficiencies. While the efficiencies are not yet competitive with other 2D perovskite materials, the PA system seems to have greater disproportion than other cations such as BA based on the EQE spectrum. ${ }^{85}$ If this property can be utilized with improved film morphology, these materials have the potential for higher $\mathrm{J}_{\mathrm{SC}}$ by absorbing a greater range of wavelengths of light. Also, it is fundamentally interesting that, when compared to the BA system, by simply removing a carbon atom from the BA spacer, the film kinetics change so dramatically. We can therefore use these materials to better understand film formation and define the techniques suitable for shorter spacer cations. A systematic comparison between the film forming properties of PA and BA films will further understanding of the disproportionation of $\mathrm{n}$ values in films, important for LED applications. ${ }^{17,87}$

\footnotetext{
ASSOCIATED CONTENT Supporting Information

Materials and methods, synthetic details, additional supplementary figures and tables about material characterization, SEM images, X-ray diffraction measurements, photoluminescence measurements, thermogravimetric analysis, profilometry measurements and film stability studies.
} 
This material is available free of charge via the Internet at http://pubs.acs.org.

\begin{abstract}
AUTHOR INFORMATION
Corresponding Authors

m-kanatzidis@,northwestern.edu

cstoumpos@materials.uoc.gr*

*Present address: Department of Materials Science and Technology, University of Crete, Heraklion GR-70013, Greece.
\end{abstract}

\title{
Notes
}

The authors declare no competing financial interest.

\section{ACKNOWLEDGMENTS}

Work on the synthesis and characterization of the materials was supported by the Office of Naval Research (ONR). This project was supported in part by a fellowship award through the National Defense Science and Engineering Graduate (NDSEG) Fellowship Program, sponsored by the Air Force Research Laboratory (AFRL), the Office of Naval Research (ONR) and the Army Research Office (ARO). Work on the solar cell fabrication and evaluation was supported by the LEAP Center, an Energy Frontier Research Center funded by the US Department of Energy, Office of Science, Office of Basic Energy Sciences (award no. DE-SC0001059). Work at Los Alamos National Laboratory (LANL) was supported by the EERE program. DFT calculations were performed at the Institut des Sciences Chimiques de Rennes, which received funding from Agence Nationale pour la Recherche (TRANSHYPERO project) and the work was granted access to the HPC resources of TGCC/CINES/IDRIS under the allocation 2018-A0030907682 made by GENCI. J.E. is a senior member of Institut Universitaire de France. This work made use of the SPID facility of Northwestern University's NUANCE Center, which has received support 
from the Soft and Hybrid Nanotechnology Experimental (SHyNE) Resource (NSF ECCS1542205); the MRSEC program (NSF DMR-1720139) at the Materials Research Center; the International Institute for Nanotechnology (IIN); the Keck Foundation; and the State of Illinois, through the IIN. This research used resources of the Advanced Photon Source, a U.S. Department of Energy (DOE) Office of Science User Facility operated for the DOE Office of Science by Argonne National Laboratory under Contract No. DE-AC02-06CH11357. 


\section{References}

1. Burschka, J.; Pellet, N.; Moon, S.-J.; Humphry-Baker, R.; Gao, P.; Nazeeruddin, M. K.; Grätzel, M., Sequential deposition as a route to high-performance perovskite-sensitized solar cells. Nature 2013, 499, 316.

2. Jeon, N. J.; Noh, J. H.; Kim, Y. C.; Yang, W. S.; Ryu, S.; Seok, S. I., Solvent engineering for high-performance inorganic-organic hybrid perovskite solar cells. Nature Materials 2014, 13,897 .

3. Liang, J.; Zhu, G.; Lu, Z.; Zhao, P.; Wang, C.; Ma, Y.; Xu, Z.; Wang, Y.; Hu, Y.; Ma, L.; Chen, T.; Tie, Z.; Liu, J.; Jin, Z., Integrated perovskite solar capacitors with high energy conversion efficiency and fast photo-charging rate. Journal of Materials Chemistry A 2018, 6 (5), 2047-2052.

4. Ball, J. M.; Lee, M. M.; Hey, A.; Snaith, H. J., Low-temperature processed mesosuperstructured to thin-film perovskite solar cells. Energy \& Environmental Science 2013, 6 (6), 1739-1743.

5. Kojima, A.; Teshima, K.; Shirai, Y.; Miyasaka, T., Organometal Halide Perovskites as Visible-Light Sensitizers for Photovoltaic Cells. Journal of the American Chemical Society 2009, $131(17), 6050-6051$.

6. Kim, H.-S.; Lee, C.-R.; Im, J.-H.; Lee, K.-B.; Moehl, T.; Marchioro, A.; Moon, S.-J.; Humphry-Baker, R.; Yum, J.-H.; Moser, J. E.; Grätzel, M.; Park, N.-G., Lead Iodide Perovskite Sensitized All-Solid-State Submicron Thin Film Mesoscopic Solar Cell with Efficiency Exceeding 9\%. Scientific Reports 2012, 2, 591. 
7. Z Zhu, H.; Fu, Y.; Meng, F.; Wu, X.; Gong, Z.; Ding, Q.; Gustafsson, M. V.; Trinh, M. T.; Jin, S.; Zhu, X. Y., Lead halide perovskite nanowire lasers with low lasing thresholds and high quality factors. Nature Materials 2015, 14, 636.

8. Lee, M. M.; Teuscher, J.; Miyasaka, T.; Murakami, T. N.; Snaith, H. J., Efficient Hybrid Solar Cells Based on Meso-Superstructured Organometal Halide Perovskites. Science 2012, 338 (6107), 643-647.

9. Wang, Y.; Fullon, R.; Acerce, M.; Petoukhoff, C. E.; Yang, J.; Chen, C.; Du, S.; Lai, S. K.; Lau, S. P.; Voiry, D.; O'Carroll, D.; Gupta, G.; Mohite, A. D.; Zhang, S.; Zhou, H.; Chhowalla, M., Solution-Processed MoS2/Organolead Trihalide Perovskite Photodetectors. Advanced Materials 2017, 29 (4), 1603995.

10. Saraf, R.; Pu, L.; Maheshwari, V., A Light Harvesting, Self-Powered Monolith Tactile Sensor Based on Electric Field Induced Effects in MAPbI3 Perovskite. Advanced Materials 2018, $30(9), 1705778$.

11. Chung, I.; Lee, B.; He, J.; Chang, R. P. H.; Kanatzidis, M. G., All-solid-state dyesensitized solar cells with high efficiency. Nature 2012, 485, 486.

12. Smith, I. C.; Hoke, E. T.; Solis-Ibarra, D.; McGehee, M. D.; Karunadasa, H. I., A Layered Hybrid Perovskite Solar-Cell Absorber with Enhanced Moisture Stability. Angewandte Chemie 2014, 126 (42), 11414-11417.

13. Cao, D. H.; Stoumpos, C. C.; Farha, O. K.; Hupp, J. T.; Kanatzidis, M. G., 2D Homologous Perovskites as Light-Absorbing Materials for Solar Cell Applications. Journal of the American Chemical Society 2015, 137 (24), 7843-7850.

14. Wang, K.; Wu, C.; Yang, D.; Jiang, Y.; Priya, S., Quasi-Two-Dimensional Halide Perovskite Single Crystal Photodetector. ACS Nano 2018, 12 (5), 4919-4929. 
15. Tsai, H.; Nie, W.; Blancon, J.-C.; Stoumpos, C. C.; Soe, C. M. M.; Yoo, J.; Crochet, J.; Tretiak, S.; Even, J.; Sadhanala, A.; Azzellino, G.; Brenes, R.; Ajayan, P. M.; Bulović, V.; Stranks, S. D.; Friend, R. H.; Kanatzidis, M. G.; Mohite, A. D., Stable Light-Emitting Diodes Using Phase-Pure Ruddlesden-Popper Layered Perovskites. Advanced Materials 2018, 30 (6), 1704217.

16. Zhang, X.; Ren, X.; Liu, B.; Munir, R.; Zhu, X.; Yang, D.; Li, J.; Liu, Y.; Smilgies, D.M.; Li, R.; Yang, Z.; Niu, T.; Wang, X.; Amassian, A.; Zhao, K.; Liu, S., Stable high efficiency two-dimensional perovskite solar cells via cesium doping. Energy \& Environmental Science 2017, 10 (10), 2095-2102.

17. Yuan, M.; Quan, L. N.; Comin, R.; Walters, G.; Sabatini, R.; Voznyy, O.; Hoogland, S.; Zhao, Y.; Beauregard, E. M.; Kanjanaboos, P.; Lu, Z.; Kim, D. H.; Sargent, E. H., Perovskite energy funnels for efficient light-emitting diodes. Nature Nanotechnology 2016, 11, 872.

18. Lanzetta, L.; Marin-Beloqui, J. M.; Sanchez-Molina, I.; Ding, D.; Haque, S. A., TwoDimensional Organic Tin Halide Perovskites with Tunable Visible Emission and Their Use in Light-Emitting Devices. ACS Energy Letters 2017, 2 (7), 1662-1668.

19. Wang, Z.; Lin, Q.; Chmiel, F. P.; Sakai, N.; Herz, L. M.; Snaith, H. J., Efficient ambientair-stable solar cells with 2D-3D heterostructured butylammonium-caesium-formamidinium lead halide perovskites. Nature Energy 2017, 2, 17135.

20. Li, P.; Zhang, Y.; Liang, C.; Xing, G.; Liu, X.; Li, F.; Liu, X.; Hu, X.; Shao, G.; Song, Y., Phase Pure 2D Perovskite for High-Performance 2D-3D Heterostructured Perovskite Solar Cells. Advanced Materials 2018, 30 (52), 1805323.

21. Chen, Y.; Sun, Y.; Peng, J.; Tang, J.; Zheng, K.; Liang, Z., 2D Ruddlesden-Popper Perovskites for Optoelectronics. Advanced Materials 2018, 30 (2), 1703487. 
22. Zhang, X.; Wu, G.; Fu, W.; Qin, M.; Yang, W.; Yan, J.; Zhang, Z.; Lu, X.; Chen, H., Orientation Regulation of Phenylethylammonium Cation Based 2D Perovskite Solar Cell with Efficiency Higher Than 11\%. Advanced Energy Materials 2018, 8 (14), 1702498.

23. Smith, M. D.; Crace, E. J.; Jaffe, A.; Karunadasa, H. I., The Diversity of Layered Halide Perovskites. Annual Review of Materials Research 2018, 48 (1), 111-136.

24. Saparov, B.; Mitzi, D. B., Organic-Inorganic Perovskites: Structural Versatility for Functional Materials Design. Chemical Reviews 2016, 116 (7), 4558-4596.

25. Katan, C.; Mercier, N.; Even, J., Quantum and Dielectric Confinement Effects in LowerDimensional Hybrid Perovskite Semiconductors. Chemical Reviews 2019, 119 (5), 3140-3192.

26. Lermer, C.; Birkhold, S. T.; Moudrakovski, I. L.; Mayer, P.; Schoop, L. M.; SchmidtMende, L.; Lotsch, B. V., Toward Fluorinated Spacers for MAPI-Derived Hybrid Perovskites: Synthesis, Characterization, and Phase Transitions of (FC2H4NH3)2PbC14. Chemistry of Materials 2016, 28 (18), 6560-6566.

27. Ruddlesden, S. N.; Popper, P., The compound Sr3Ti2O7 and its structure. Acta Crystallographica 1958, 11 (1), 54-55.

28. Mao, L.; Ke, W.; Pedesseau, L.; Wu, Y.; Katan, C.; Even, J.; Wasielewski, M. R.; Stoumpos, C. C.; Kanatzidis, M. G., Hybrid Dion-Jacobson 2D Lead Iodide Perovskites. Journal of the American Chemical Society 2018, 140 (10), 3775-3783.

29. Nazarenko, O.; Kotyrba, M. R.; Wörle, M.; Cuervo-Reyes, E.; Yakunin, S.; Kovalenko, M. V., Luminescent and Photoconductive Layered Lead Halide Perovskite Compounds Comprising Mixtures of Cesium and Guanidinium Cations. Inorganic Chemistry 2017, 56 (19), $11552-11564$. 
30. Soe, C. M. M.; Stoumpos, C. C.; Kepenekian, M.; Traoré, B.; Tsai, H.; Nie, W.; Wang, B.; Katan, C.; Seshadri, R.; Mohite, A. D.; Even, J.; Marks, T. J.; Kanatzidis, M. G., New Type of 2D Perovskites with Alternating Cations in the Interlayer Space,

$(\mathrm{C}(\mathrm{NH} 2) 3)(\mathrm{CH} 3 \mathrm{NH} 3) n \mathrm{PbnI} 3 \mathrm{n}+1$ : Structure, Properties, and Photovoltaic Performance. Journal of the American Chemical Society 2017, 139 (45), 16297-16309.

31. Li, X.; Hoffman, J.; Ke, W.; Chen, M.; Tsai, H.; Nie, W.; Mohite, A. D.; Kepenekian, M.; Katan, C.; Even, J.; Wasielewski, M. R.; Stoumpos, C. C.; Kanatzidis, M. G., TwoDimensional Halide Perovskites Incorporating Straight Chain Symmetric Diammonium Ions, $(\mathrm{NH} 3 \mathrm{CmH} 2 \mathrm{mNH} 3)(\mathrm{CH} 3 \mathrm{NH} 3) \mathrm{n}-1 \mathrm{PbnI} 3 \mathrm{n}+1(\mathrm{~m}=4-9 ; \mathrm{n}=1-4)$. Journal of the American Chemical Society 2018, 140 (38), 12226-12238.

32. Mao, L.; Wu, Y.; Stoumpos, C. C.; Wasielewski, M. R.; Kanatzidis, M. G., White-Light Emission and Structural Distortion in New Corrugated Two-Dimensional Lead Bromide Perovskites. Journal of the American Chemical Society 2017, 139 (14), 5210-5215.

33. Li, Y. Y.; Lin, C. K.; Zheng, G. L.; Cheng, Z. Y.; You, H.; Wang, W. D.; Lin, J., Novel $\langle 110\rangle$-Oriented Organic-Inorganic Perovskite Compound Stabilized by N-(3Aminopropyl)imidazole with Improved Optical Properties. Chemistry of Materials 2006, 18 (15), 3463-3469.

34. A. Mousdis, G.; Gionis, V.; C. Papavassiliou, G.; P. Raptopoulou, C.; Terzis, A., Preparation, structure and optical properties of [CH3SC(=NH2)NH2]3PbI5, $[\mathrm{CH} 3 \mathrm{SC}(=\mathrm{NH} 2) \mathrm{NH} 2] 4 \mathrm{~Pb} 2 \mathrm{Br} 8$ and $[\mathrm{CH} 3 \mathrm{SC}(=\mathrm{NH} 2) \mathrm{NH} 2] 3 \mathrm{PbCl} \cdot \mathrm{CH} 3 \mathrm{SC}(=\mathrm{NH} 2) \mathrm{NH} 2 \mathrm{Cl}$. Journal of Materials Chemistry 1998, 8 (10), 2259-2262. 
35. Li, Y.; Zheng, G.; Lin, J., Synthesis, Structure, and Optical Properties of a Contorted $<110>-$ Oriented Layered Hybrid Perovskite: C3H11SN3PbBr4. European Journal of Inorganic Chemistry 2008, 2008 (10), 1689-1692.

36. Dohner, E. R.; Hoke, E. T.; Karunadasa, H. I., Self-Assembly of Broadband White-Light Emitters. Journal of the American Chemical Society 2014, 136 (5), 1718-1721.

37. Dohner, E. R.; Jaffe, A.; Bradshaw, L. R.; Karunadasa, H. I., Intrinsic White-Light Emission from Layered Hybrid Perovskites. Journal of the American Chemical Society 2014, $136(38), 13154-13157$.

38. Mitzi, D. B.; Wang, S.; Feild, C. A.; Chess, C. A.; Guloy, A. M., Conducting Layered Organic-inorganic Halides Containing $<110>$-Oriented Perovskite Sheets. Science 1995, 267 (5203), 1473.

39. Wang, S.; Mitzi, D. B.; Feild, C. A.; Guloy, A., Synthesis and Characterization of $[\mathrm{NH} 2 \mathrm{C}(\mathrm{I})=\mathrm{NH} 2] 3 \mathrm{MI} 5(\mathrm{M}=\mathrm{Sn}, \mathrm{Pb})$ : Stereochemical Activity in Divalent Tin and Lead Halides Containing Single Perovskite Sheets. Journal of the American Chemical Society 1995, 117 (19), $5297-5302$.

40. Li, Y.; Zheng, G.; Lin, C.; Lin, J., Synthesis, structure and optical properties of different dimensional organic-inorganic perovskites. Solid State Sci. 2007, 9, 855-861.

41. Stoumpos, C. C.; Cao, D. H.; Clark, D. J.; Young, J.; Rondinelli, J. M.; Jang, J. I.; Hupp, J. T.; Kanatzidis, M. G., Ruddlesden-Popper Hybrid Lead Iodide Perovskite 2D Homologous Semiconductors. Chemistry of Materials 2016, 28 (8), 2852-2867.

42. Byun, J.; Cho, H.; Wolf, C.; Jang, M.; Sadhanala, A.; Friend, R. H.; Yang, H.; Lee, T.W., Efficient Visible Quasi-2D Perovskite Light-Emitting Diodes. Advanced Materials 2016, 28 (34), 7515-7520. 
43. Lee, H.-D.; Kim, H.; Cho, H.; Cha, W.; Hong, Y.; Kim, Y.-H.; Sadhanala, A.;

Venugopalan, V.; Kim, J. S.; Choi, J. W.; Lee, C.-L.; Kim, D.; Yang, H.; Friend, R. H.; Lee, T.W., Efficient Ruddlesden-Popper Perovskite Light-Emitting Diodes with Randomly Oriented Nanocrystals. Advanced Functional Materials 2019, 1901225.

44. Stoumpos, C. C.; Mao, L.; Malliakas, C. D.; Kanatzidis, M. G., Structure-Band Gap Relationships in Hexagonal Polytypes and Low-Dimensional Structures of Hybrid Tin Iodide Perovskites. Inorganic Chemistry 2017, 56 (1), 56-73.

45. Ke, W.; Stoumpos, C. C.; Spanopoulos, I.; Mao, L.; Chen, M.; Wasielewski, M. R.; Kanatzidis, M. G., Efficient Lead-Free Solar Cells Based on Hollow \{en\}MASnI3 Perovskites. Journal of the American Chemical Society 2017, 139 (41), 14800-14806.

46. Spanopoulos, I.; Ke, W.; Stoumpos, C. C.; Schueller, E. C.; Kontsevoi, O. Y.; Seshadri, R.; Kanatzidis, M. G., Unraveling the Chemical Nature of the 3D "Hollow" Hybrid Halide Perovskites. Journal of the American Chemical Society 2018, 140 (17), 5728-5742.

47. Ke, W.; Stoumpos, C. C.; Spanopoulos, I.; Chen, M.; Wasielewski, M. R.; Kanatzidis, M. G., Diammonium Cations in the FASnI3 Perovskite Structure Lead to Lower Dark Currents and More Efficient Solar Cells. ACS Energy Letters 2018, 3 (7), 1470-1476.

48. Leblanc, A.; Mercier, N.; Allain, M.; Dittmer, J.; Fernandez, V.; Pauporté, T., Lead- and Iodide-Deficient (CH3NH3)PbI3 (d-MAPI): The Bridge between 2D and 3D Hybrid Perovskites. Angewandte Chemie International Edition 2017, 56 (50), 16067-16072.

49. Kamminga, M. E.; Fang, H.-H.; Filip, M. R.; Giustino, F.; Baas, J.; Blake, G. R.; Loi, M. A.; Palstra, T. T. M., Confinement Effects in Low-Dimensional Lead Iodide Perovskite Hybrids. Chemistry of Materials 2016, 28 (13), 4554-4562. 
50. Lode, C.; Krautscheid, H., Iodostannate mit polymeren Anionen: $\left(\mathrm{Me}_{3} \mathrm{PhN}\right)_{4}{ }^{2 \infty}\left[\mathrm{Sn}_{3} \mathrm{I}_{10}\right]$, $\left[\mathrm{Me}_{2} \mathrm{HN}-\left(\mathrm{CH}_{2}\right)_{2}-\mathrm{NMe}_{2} \mathrm{H}\right]_{2}{ }^{1 \infty}\left[\mathrm{Sn}_{3} \mathrm{I}_{10}\right],\left[\mathrm{Me}_{2} \mathrm{HN}-\left(\mathrm{CH}_{2}\right)_{2}-\mathrm{NMe}_{2} \mathrm{H}\right]^{2 \infty}\left[\mathrm{Sn}_{3} \mathrm{I}_{8}\right]$. Z. Anorg. Allg. Chem. 2001, 627.

51. Wiest, T.; Blachnik, R.; Reuter, H., Die Kristallstruktur von [PhMe3N]4[Pb3Br10]/ Crystal Structure of [PhMe3N]4[Pb3Br10]. In Zeitschrift für Naturforschung B, 1999; Vol. 54, p 1099.

52. Yuan, Z.; Zhou, C.; Tian, Y.; Shu, Y.; Messier, J.; Wang, J. C.; van de Burgt, L. J.;

Kountouriotis, K.; Xin, Y.; Holt, E.; Schanze, K.; Clark, R.; Siegrist, T.; Ma, B., Onedimensional organic lead halide perovskites with efficient bluish white-light emission. Nature Communications 2017, 8, 14051.

53. Kamminga, M. E.; de Wijs, G. A.; Havenith, R. W. A.; Blake, G. R.; Palstra, T. T. M., The Role of Connectivity on Electronic Properties of Lead Iodide Perovskite-Derived Compounds. Inorganic Chemistry 2017, 56 (14), 8408-8414.

54. Spanopoulos, I.; Hadar, I.; Ke, W.; Tu, Q.; Chen, M.; Tsai, H.; He, Y.; Shekhawat, G.; Dravid, V. P.; Wasielewski, M. R.; Mohite, A. D.; Stoumpos, C. C.; Kanatzidis, M. G., Uniaxial Expansion of the 2D Ruddlesden-Popper Perovskite Family for Improved Environmental Stability. Journal of the American Chemical Society 2019.

55. Zhang, Y.; Li, F.; Jiang, K.-J.; Huang, J.-H.; Wang, H.; Fan, H.; Wang, P.; Liu, C.-M.; Zhang, L.-P.; Song, Y., From 2D to 3D: a facile and effective procedure for fabrication of planar CH3NH3PbI3 perovskite solar cells. Journal of Materials Chemistry A 2018, 6 (37), 1786717873. 
56. Nie, W.; Tsai, H.; Asadpour, R.; Blancon, J.-C.; Neukirch, A. J.; Gupta, G.; Crochet, J. J.; Chhowalla, M.; Tretiak, S.; Alam, M. A.; Wang, H.-L.; Mohite, A. D., High-efficiency solutionprocessed perovskite solar cells with millimeter-scale grains. Science 2015, 347 (6221), 522.

57. Soe, C. M. M.; Nie, W.; Stoumpos, C. C.; Tsai, H.; Blancon, J.-C.; Liu, F.; Even, J.;

Marks, T. J.; Mohite, A. D.; Kanatzidis, M. G., Understanding Film Formation Morphology and Orientation in High Member 2D Ruddlesden-Popper Perovskites for High-Efficiency Solar Cells. Advanced Energy Materials 2018, 8 (1), 1700979.

58. Petříček, V.; Dušek, M.; Palatinus, L., Crystallographic Computing System JANA2006: General features. Zeitschrift für Kristallographie - Crystalline Materials 2014, 229 (5), 345.

59. Spek, A., Structure validation in chemical crystallography. Acta Crystallographica Section D 2009, 65 (2), 148-155.

60. Soler, J. M.; Artacho, E.; Gale, J. D.; García, A.; Junquera, J.; Ordejón, P.; SánchezPortal, D., The SIESTA method for ab initio order-N materials simulation. Journal of Physics: Condensed Matter 2002, 14 (11), 2745-2779.

61. Artacho, E.; Anglada, E.; Diéguez, O.; Gale, J. D.; García, A.; Junquera, J.; Martin, R. M.; Ordejón, P.; Pruneda, J. M.; Sánchez-Portal, D.; Soler, J. M., The SIESTA method; Developments and applicability. Journal of Physics: Condensed Matter 2008, 20 (6), 064208. 62. Zhang, Y.; Yang, W., Comment on "Generalized Gradient Approximation Made Simple". Physical Review Letters 1998, 80 (4), 890.

63. Troullier, N.; Martins, J. L., Efficient pseudopotentials for plane-wave calculations. Physical Review B 1991, 43 (3), 1993-2006. 
64. Artacho, E.; Sánchez-Portal, D.; Ordejón, P.; García, A.; Soler, J. M., Linear-Scaling abinitio Calculations for Large and Complex Systems. Physica Status Solidi (b) 1999, 215 (1), 809817.

65. Fernández-Seivane, L.; Oliveira, M. A.; Sanvito, S.; Ferrer, J., On-site approximation for spin-orbit coupling in linear combination of atomic orbitals density functional methods. Journal of Physics: Condensed Matter 2006, 18 (34), 7999-8013.

66. Macrae, C. F.; Edgington, P. R.; McCabe, P.; Pidcock, E.; Shields, G. P.; Taylor, R.; Towler, M.; van de Streek, J., Mercury: visualization and analysis of crystal structures. Journal of Applied Crystallography 2006, 39 (3), 453-457.

67. Jiang, Z., GIXSGUI: a MATLAB toolbox for grazing-incidence X-ray scattering data visualization and reduction, and indexing of buried three-dimensional periodic nanostructured films. Journal of Applied Crystallography 2015, 48 (3), 917-926.

68. Billing, D. G.; Lemmerer, A., Octakis(3-propylammonium) octadecaiodopentaplumbate(II): a new layered stucture based on layered perovskites. Acta Crystallographica Section C 2006, 62 (6), m238-m240.

69. D. B. Mitzi, S. W., C. A. Feild, C. A. Chess and A. M. Guloy, Conducting Layered Organic-Inorganic Halides Containing <110>-Oriented Perovskite Sheets. Science 1995, 267, $1473-1476$.

70. Dinh Do, N.; Kovalchukova, O.; Stash, A.; Strashnova, S., catena-Poly[ammonium [aqua-bis-( $\mu$-2,3,5,6-tetra-oxo-4-nitro-pyridin-4-ido)argentate(I)]]. Acta Crystallographica Section E: Structure Reports Online 2013, 69 (Pt 8), m477-m478.

71. Li, J.; Stoumpos, C. C.; Trimarchi, G. G.; Chung, I.; Mao, L.; Chen, M.; Wasielewski, M. R.; Wang, L.; Kanatzidis, M. G., Air-Stable Direct Bandgap Perovskite Semiconductors: All- 
Inorganic Tin-Based Heteroleptic Halides AxSnClyIz $(\mathrm{A}=\mathrm{Cs}, \mathrm{Rb})$. Chemistry of Materials 2018, 30 (14), 4847-4856.

72. Billing, D. G.; Lemmerer, A., Synthesis, characterization and phase transitions in the inorganic-organic layered perovskite-type hybrids [(CnH2n+1NH3)2PbI4], $\mathrm{n}=4,5$ and 6 . Acta Crystallographica Section B 2007, 63 (5), 735-747.

73. J. Even, L. P., M.-A. Dupertuis, J.-M. Jancu, and C. Katan, Electronic model for selfassembled hybrid organic/perovskite semiconductors: Reverse band edge electronic states ordering and spin-orbit coupling. Phys. Rev. B 2012, 86, 205301.

74. Kikuchi, K.; Takeoka, Y.; Rikukawa, M.; Sanui, K., Structure and optical properties of lead iodide based two-dimensional perovskite compounds containing fluorophenethylamines. Current Applied Physics 2004, 4 (6), 599-602.

75. Blancon, J. C.; Tsai, H.; Nie, W.; Stoumpos, C. C.; Pedesseau, L.; Katan, C.; Kepenekian, M.; Soe, C. M. M.; Appavoo, K.; Sfeir, M. Y.; Tretiak, S.; Ajayan, P. M.; Kanatzidis, M. G.; Even, J.; Crochet, J. J.; Mohite, A. D., Extremely efficient internal exciton dissociation through edge states in layered 2D perovskites. Science 2017, 355 (6331), 12881292.

76. Stoumpos, C. C.; Malliakas, C. D.; Kanatzidis, M. G., Semiconducting Tin and Lead Iodide Perovskites with Organic Cations: Phase Transitions, High Mobilities, and Near-Infrared Photoluminescent Properties. Inorganic Chemistry 2013, 52 (15), 9019-9038.

77. Daub, M.; Haber, C.; Hillebrecht, H., Synthesis, Crystal Structures, Optical Properties, and Phase Transitions of the Layered Guanidinium-Based Hybrid Perovskites [C(NH2)3]2MI4; $\mathrm{M}=\mathrm{Sn}, \mathrm{Pb}$. European Journal of Inorganic Chemistry 2017, 2017 (7), 1120-1126. 
78. Leveillee, J.; Katan, C.; Zhou, L.; Mohite, A.; Even, J.; Tretiak, S.; Scheife, A.;

Neukirch, A. J., Influence of $\pi$-conjugated cations and halogen substitution on the optoelectronic and excitonic properties of layered hybrid perovskites. Physical Review Materials 2018, 2 (10), 105406.

79. Tress, W.; Marinova, N.; Moehl, T.; Zakeeruddin, S. M.; Nazeeruddin, M. K.; Grätzel, M., Understanding the rate-dependent J-V hysteresis, slow time component, and aging in $\mathrm{CH} 3 \mathrm{NH} 3 \mathrm{PbI} 3$ perovskite solar cells: the role of a compensated electric field. Energy \& Environmental Science 2015, 8 (3), 995-1004.

80. Mizusaki, J.; Arai, K.; Fueki, K., Ionic conduction of the perovskite-type halides. Solid State Ionics 1983, 11 (3), 203-211.

81. Li, X.; Benedek, N. A., Enhancement of Ionic Transport in Complex Oxides through Soft Lattice Modes and Epitaxial Strain. Chemistry of Materials 2015, 27 (7), 2647-2652.

82. Constantinos C. Stoumpos, D. H. C., Daniel J. Clark, Joshua Young, James M. Rondinelli, Joon I. Jang, Joseph T. Hupp, and Mercouri G. Kanatzidis, Ruddlesden-Popper Hybrid Lead Iodide Perovskite 2D Homologous Semiconductors. Chem. Mater. 2016, 28, $2852-2867$.

83. Knop, O.; Wasylishen, R. E.; White, M. A.; Cameron, T. S.; Oort, M. J. M. V., Alkylammonium lead halides. Part 2. $\mathrm{CH} 3 \mathrm{NH} 3 \mathrm{PbX} 3(\mathrm{X}=\mathrm{Cl}, \mathrm{Br}, \mathrm{I})$ perovskites: cuboctahedral halide cages with isotropic cation reorientation. Canadian Journal of Chemistry 1990, 68 (3), $412-422$.

84. Smith, I. C.; Smith, M. D.; Jaffe, A.; Lin, Y.; Karunadasa, H. I., Between the Sheets: Postsynthetic Transformations in Hybrid Perovskites. Chemistry of Materials 2017, 29 (5), 18681884. 
85. Tsai, H.; Nie, W.; Blancon, J.-C.; Stoumpos, C. C.; Asadpour, R.; Harutyunyan, B.; Neukirch, A. J.; Verduzco, R.; Crochet, J. J.; Tretiak, S.; Pedesseau, L.; Even, J.; Alam, M. A.; Gupta, G.; Lou, J.; Ajayan, P. M.; Bedzyk, M. J.; Kanatzidis, M. G.; Mohite, A. D., Highefficiency two-dimensional Ruddlesden-Popper perovskite solar cells. Nature 2016, 536, 312. 86. Zheng, K.; Chen, Y.; Sun, Y.; Chen, J.; Chábera, P.; Schaller, R.; Al-Marri, M. J.; Canton, S. E.; Liang, Z.; Pullerits, T., Inter-phase charge and energy transfer in RuddlesdenPopper 2D perovskites: critical role of the spacing cations. Journal of Materials Chemistry A 2018, 6 (15), 6244-6250.

87. Wang, N.; Cheng, L.; Ge, R.; Zhang, S.; Miao, Y.; Zou, W.; Yi, C.; Sun, Y.; Cao, Y.; Yang, R.; Wei, Y.; Guo, Q.; Ke, Y.; Yu, M.; Jin, Y.; Liu, Y.; Ding, Q.; Di, D.; Yang, L.; Xing, G.; Tian, H.; Jin, C.; Gao, F.; Friend, R. H.; Wang, J.; Huang, W., Perovskite light-emitting diodes based on solution-processed self-organized multiple quantum wells. Nature Photonics 2016, 10, 699. 
Tables

\section{Table 1. Crystal Data and Structure Refinement for PA Materials.}

\begin{tabular}{|c|c|c|c|c|c|}
\hline & $(\mathrm{PA})_{3} \mathrm{~Pb}_{2} \mathrm{I}_{7}$ & $m=3$ & $m=4$ & $n=3$ & $n=4$ \\
\hline Empirical formula & $\mathrm{C}_{9} \mathrm{H}_{30} \mathrm{I}_{7} \mathrm{~N}_{3} \mathrm{~Pb}_{2}$ & $\mathrm{C}_{32} \mathrm{H}_{106} \mathrm{I}_{25} \mathrm{~N}_{11} \mathrm{~Pb}_{7}$ & $\mathrm{C}_{38} \mathrm{H}_{132} \mathrm{I}_{32} \mathrm{~N}_{14} \mathrm{~Pb}_{9}$ & $\mathrm{C}_{8} \mathrm{H}_{32} \mathrm{I}_{10} \mathrm{~N}_{4} \mathrm{~Pb}_{3}$ & $\mathrm{C}_{9} \mathrm{H}_{38} \mathrm{~N}_{5} \mathrm{~Pb}_{4} \mathrm{I}_{13}$ \\
\hline Formula weight & 1483 & 5268 & 6727 & 2075 & 2695 \\
\hline Temperature (K) & 293 & 293 & 293 & 293 & 293 \\
\hline Wavelength $(\AA)$ & 0.71073 & 0.71073 & 0.71073 & 0.71073 & 0.71073 \\
\hline Crystal system & orthorhombic & monoclinic & monoclinic & monoclinic & monoclinic \\
\hline Space group & $P 2{ }_{1} 2_{1} 2_{1}$ & $P 2 / c$ & $C 2$ & $P 2_{1} / a$ & $C c$ \\
\hline Crystal Shape & White & Needles & Needles & Plates & Plates \\
\hline Crystal Color & Needles & Orange & Red & Dark Red & Black \\
\hline \multirow{4}{*}{$\begin{array}{l}\text { Unit cell dimensions } \\
(\AA)\end{array}$} & $\mathrm{a}=8.79150(10)$ & $\mathrm{a}=19.2010(17)$ & $\mathrm{a}=45.276(2)$ & $\mathrm{a}=8.850(4)$ & $a=62.405(5)$ \\
\hline & $\mathrm{b}=15.3917(3)$ & $\mathrm{b}=8.8414(5)$ & $\mathrm{b}=8.8555(3)$ & $\mathrm{b}=8.9262(8)$ & $\mathrm{b}=8.9358(7)$ \\
\hline & $c=22.3423(4)$ & $\mathrm{c}=37.707(3)$ & $\mathrm{c}=19.1635(10)$ & $c=25.0700(10)$ & $\mathrm{c}=8.8712(6)$ \\
\hline & & $\beta=119.351(9)^{\circ}$ & $\beta=113.372(4)^{\circ}$ & $\beta=96.474(11)^{\circ}$ & $\beta=92.947(6)^{\circ}$ \\
\hline Volume $\left(\AA^{3}\right)$ & $3023.27(9)$ & $5579.5(9)$ & $7053.1(6)$ & $1967.9(9)$ & $4940.4(6)$ \\
\hline $\mathrm{Z}$ & 4 & 2 & 2 & 2 & 4 \\
\hline $\begin{array}{l}\text { Density (calculated, } \\
\mathrm{g} / \mathrm{cm}^{3} \text { ) }\end{array}$ & 3.2583 & 3.1358 & 3.1676 & 3.5018 & 3.6152 \\
\hline $\begin{array}{l}\text { Absorption } \\
\text { coefficient }\left(\mathrm{mm}^{-1}\right)\end{array}$ & 18.27 & 17.464 & 17.731 & 20.65 & 21.724 \\
\hline $\mathrm{F}(000)$ & 2560 & 4536 & 5784 & 1768 & 4576 \\
\hline Crystal size $\left(\mathrm{mm}^{3}\right)$ & $\begin{array}{l}0.042 \times 0.049 \times \\
0.110\end{array}$ & $\begin{array}{l}0.018 \times 0.055 \times \\
0.030\end{array}$ & $\begin{array}{l}0.061 \times 0.023 \times \\
0.018\end{array}$ & $\begin{array}{l}0.587 \times 0.462 \times \\
0.024\end{array}$ & $\begin{array}{l}0.012 \times 0.176 \\
\times 0.188\end{array}$ \\
\hline $\begin{array}{l}\theta \text { range for data } \\
\text { collection }\left({ }^{\circ}\right)\end{array}$ & 1.61 to $23.4^{\circ}$ & 2.12 to $29.27^{\circ}$ & 1.79 to 29.27 & 2.81 to $29.27^{\circ}$ & 1.96 to 29.26 \\
\hline Index ranges & $\begin{array}{l}-9 \leq \mathrm{h} \leq 9 \\
-17 \leq \mathrm{k} \leq 17 \\
-24 \leq 1 \leq 24\end{array}$ & $\begin{array}{l}-26 \leq \mathrm{h} \leq 26 \\
-10 \leq \mathrm{k} \leq 12 \\
-51 \leq 1 \leq 51\end{array}$ & $\begin{array}{l}-61 \leq \mathrm{h} \leq 61 \\
-12 \leq \mathrm{k} \leq 12 \\
-26 \leq 1 \leq 26\end{array}$ & $\begin{array}{l}-11 \leq \mathrm{h} \leq 12 \\
-12 \leq \mathrm{k} \leq 12 \\
-34 \leq 1 \leq 33\end{array}$ & $\begin{array}{l}-85 \leq \mathrm{h} \leq 85 \\
-12 \leq \mathrm{k} \leq 12 \\
-11 \leq 1 \leq 11\end{array}$ \\
\hline Reflections collected & 73278 & 51123 & 34061 & 12017 & 19790 \\
\hline $\begin{array}{l}\text { Independent } \\
\text { reflections }\end{array}$ & $\begin{array}{l}4406 \\
{\left[\mathrm{R}_{\text {int }}=0.0735\right]}\end{array}$ & $\begin{array}{l}10105 \\
{\left[\mathrm{R}_{\mathrm{int}}=0.3233\right]}\end{array}$ & $\begin{array}{l}12755 \\
{\left[\mathrm{R}_{\mathrm{int}}=0.0892\right]}\end{array}$ & $\begin{array}{l}2798 \\
{\left[\mathrm{R}_{\mathrm{int}}=0.1657\right]}\end{array}$ & $\begin{array}{l}7973 \\
{\left[\mathrm{R}_{\text {int }}=0.1462\right]}\end{array}$ \\
\hline $\begin{array}{l}\text { Completeness to } \theta= \\
29.27^{\circ}\end{array}$ & $100 \%$ & $99 \%$ & $99 \%$ & $82 \%$ & $98 \%$ \\
\hline Refinement method & $\begin{array}{l}\text { Full-matrix } \\
\text { least-squares on } \\
\mathrm{F}^{2}\end{array}$ & $\begin{array}{l}\text { Full-matrix } \\
\text { least-squares on } \\
\mathrm{F}^{2}\end{array}$ & $\begin{array}{l}\text { Full-matrix } \\
\text { least-squares on } \\
\mathrm{F}^{2}\end{array}$ & $\begin{array}{l}\text { Full-matrix } \\
\text { least-squares on } \\
\mathrm{F}^{2}\end{array}$ & $\begin{array}{l}\text { Full-matrix } \\
\text { least-squares } \\
\text { on } \mathrm{F}^{2}\end{array}$ \\
\hline $\begin{array}{l}\text { Data / restraints / } \\
\text { parameters }\end{array}$ & $4406 / 15 / 121$ & $10105 / 26 / 214$ & $12755 / 31 / 267$ & $2798 / 6 / 82$ & $7973 / 13 / 203$ \\
\hline Goodness-of-fit & 1.13 & 0.32 & 3.00 & 3.43 & 2.62 \\
\hline $\begin{array}{l}\text { Final R indices } \\
{[I>3 \sigma(I)]}\end{array}$ & $\begin{array}{l}\mathrm{R}_{\mathrm{obs}}=0.0268 \\
\mathrm{wR}_{\mathrm{obs}}=0.0546\end{array}$ & $\begin{array}{l}\mathrm{R}_{\text {obs }}=0.0361 \\
\mathrm{wR}_{\text {obs }}=0.0817\end{array}$ & $\begin{array}{l}\mathrm{R}_{\text {obs }}=0.1077 \\
\mathrm{wR}_{\mathrm{obs}}=0.1973\end{array}$ & $\begin{array}{l}\mathrm{R}_{\text {obs }}=0.0851 \\
\mathrm{wR}_{\mathrm{obs}}=0.1893\end{array}$ & $\begin{array}{l}\mathrm{R}_{\mathrm{obs}}=0.1161 \\
\mathrm{wR}_{\mathrm{obs}}=0.2277\end{array}$ \\
\hline $\mathrm{R}$ indices [all data] & $\begin{array}{l}\mathrm{R}_{\mathrm{all}}=0.0401 \\
\mathrm{wR}_{\mathrm{all}}=0.0585\end{array}$ & $\begin{array}{l}\mathrm{R}_{\mathrm{all}}=0.4073 \\
\mathrm{wR}_{\text {all }}=0.2329\end{array}$ & $\begin{array}{l}\mathrm{R}_{\mathrm{all}}=0.1940 \\
\mathrm{wR}_{\text {all }}=0.2113\end{array}$ & $\begin{array}{l}\mathrm{R}_{\mathrm{all}}=0.1247 \\
\mathrm{wR}_{\text {all }}=0.1910\end{array}$ & $\begin{array}{l}\mathrm{R}_{\mathrm{all}}=0.2447 \\
\mathrm{wR}_{\mathrm{all}}=0.2460\end{array}$ \\
\hline
\end{tabular}




\begin{tabular}{|c|c|c|c|c|c|}
\hline $\begin{array}{l}\text { Largest diff. peak and } \\
\text { hole }\left(\mathrm{e} \cdot \AA^{-3}\right)\end{array}$ & 0.52 and -0.47 & 1.45 and -1.39 & 5.98 and -4.04 & 1.98 and -2.61 & 8.26 and -5.97 \\
\hline
\end{tabular}

\section{Figures}

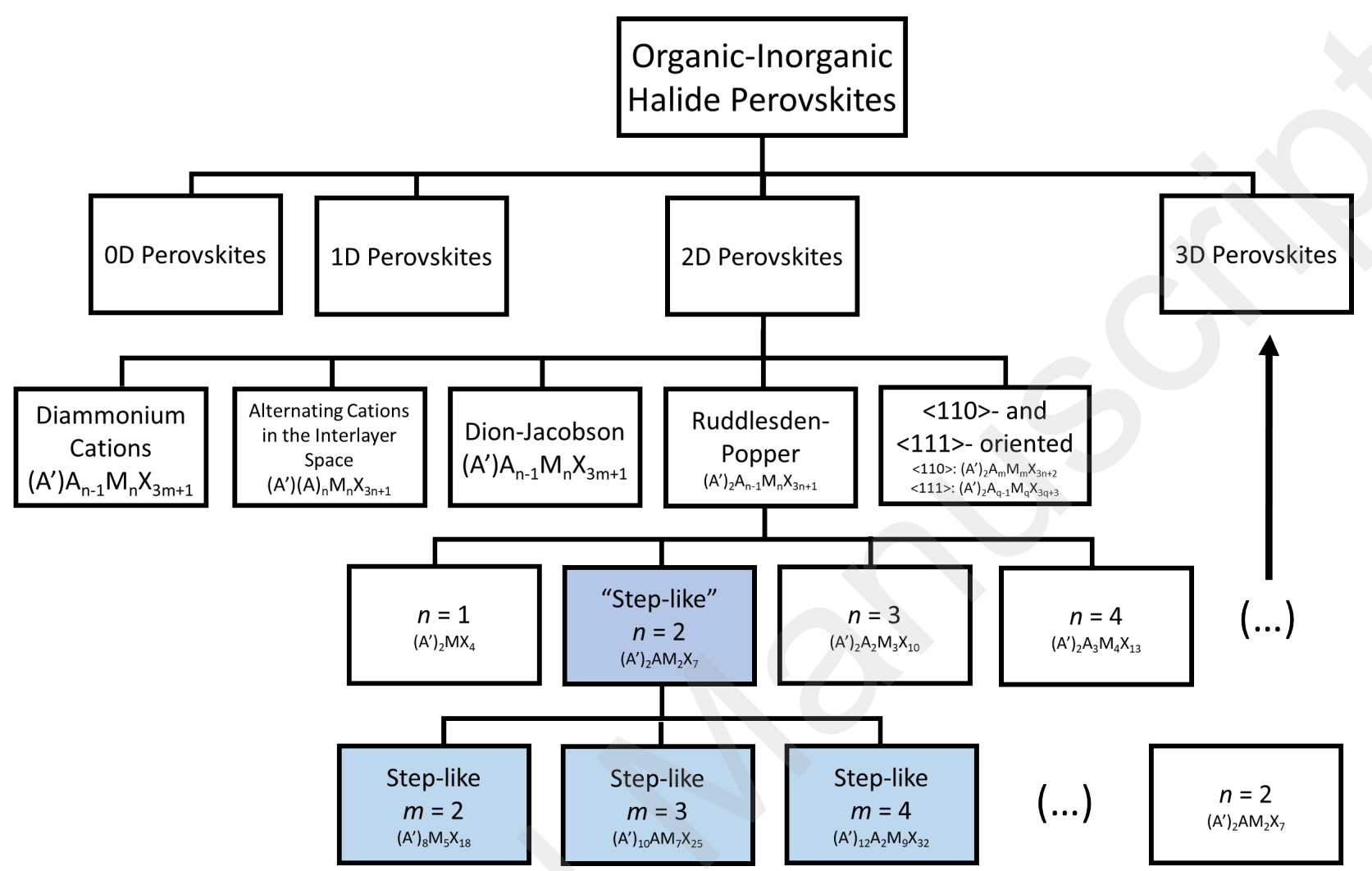

Scheme 1. A partial hierarchy diagram of different halide perovskite phases resulting from different spacing cations. Boxes labelled in blue represent materials with face-sharing octahedra. The first line divides the structure types by dimensionality. The 2D structure types are then divided into several categories based on spacing cations and cleaving direction. One of these categories, RP perovskites, is expanded upon here to show the various thicknesses $\mathrm{n}$ which can form within the category, which is the structure type of the $n>2$ PA series. When $n$ approaches $\infty$, the structure collapses to the so-called $3 \mathrm{D} \mathrm{GdFeO}_{3}$ structure types. The Ruddlesden-Popper " $n$ $=2$ " PA structure is replaced by the perovskitoid series of SL materials with width $\mathrm{m}$. As $\mathrm{m}$ approaches $\infty$, the structure collapse to " $n=2$." 

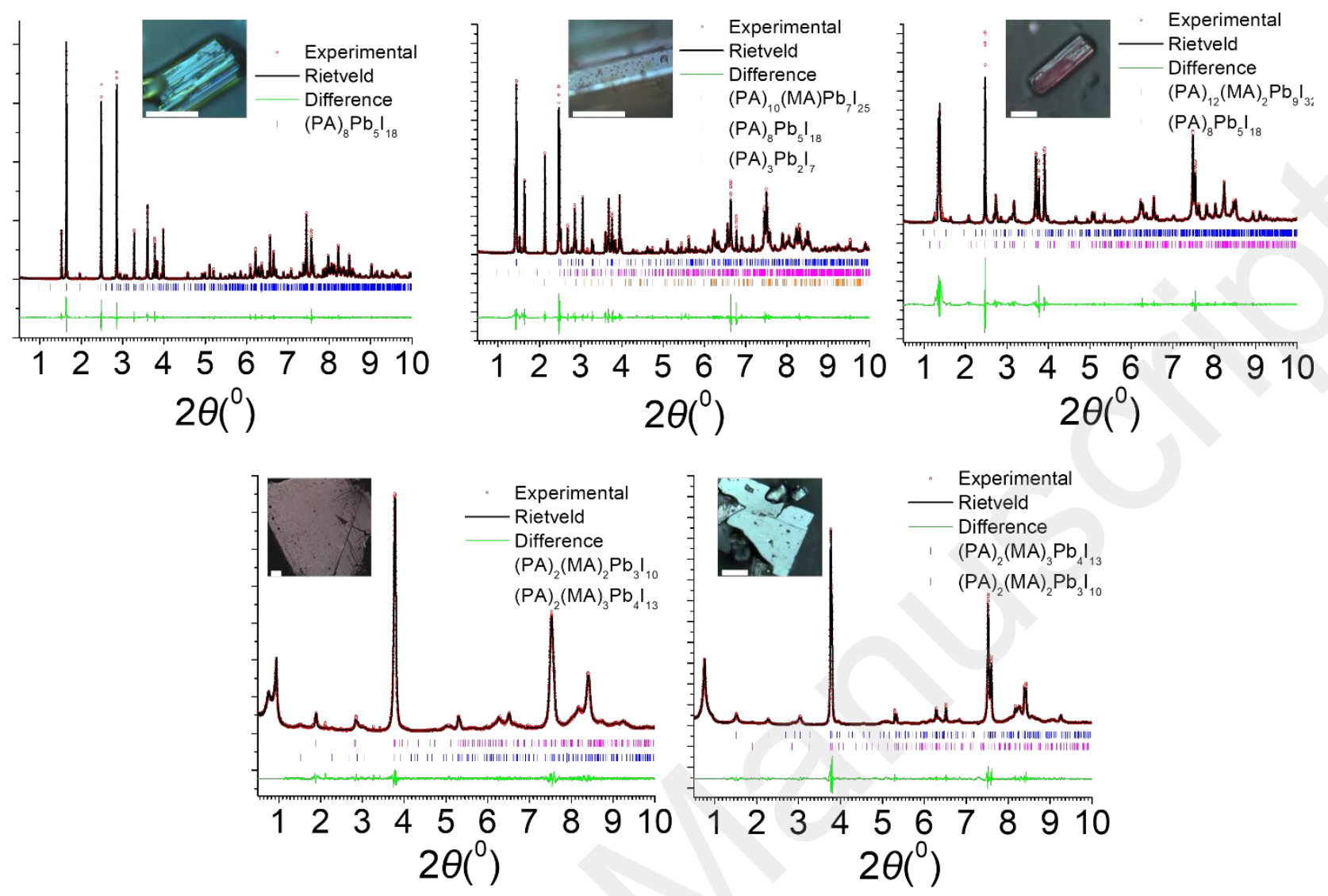

Figure 1. Rietveld analysis of synchrotron-quality PXRD data for each of the five explored structures. For $n=4$, the low angle peak was not able to be resolved because it was disproportionately intense, so it was excluded from the calculations. Scale bar for inset images is $1 \mathrm{~mm}$. 

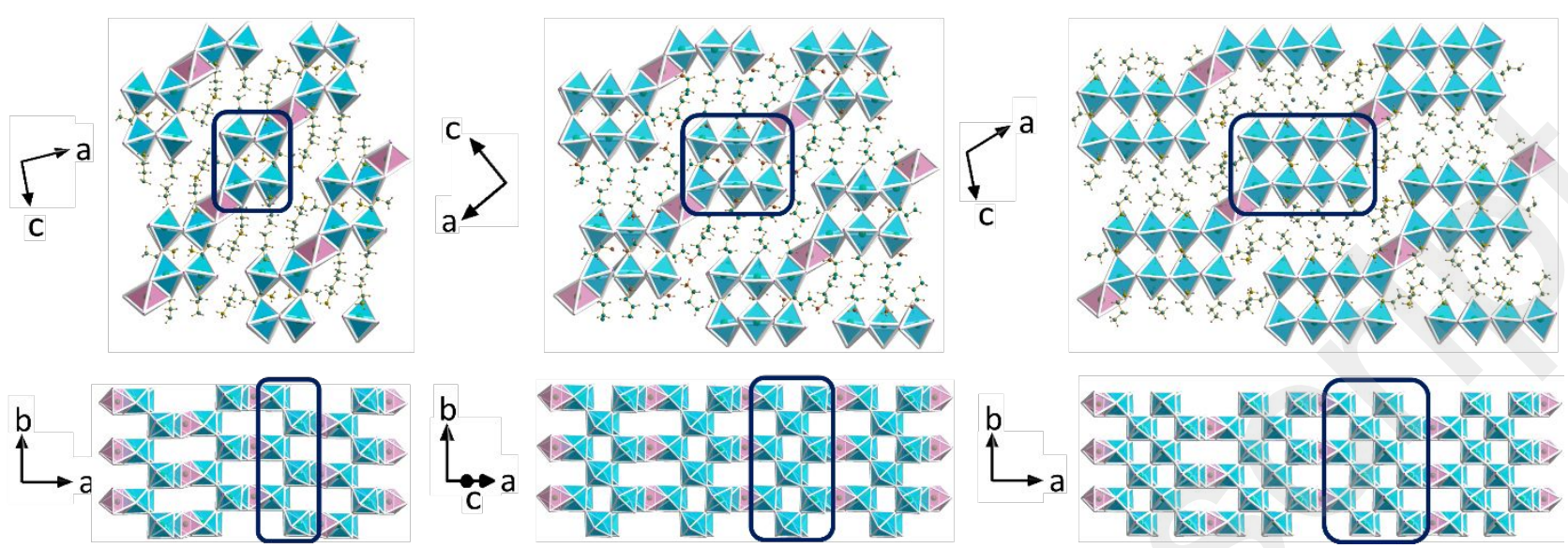

Figure 2. The homologous series of SL materials. The blue octahedra are at least partially corner-sharing and the pink octahedra are fully face-sharing. The top row shows structures looking down the b-axis perpendicular to the $1 \mathrm{D}$ corner-sharing chains. The bottom row shows the structures down the c-axis (excluding $\mathrm{m}=3$ ), parallel to the chains and emphasizing the $<110>$ cleavage of the chains by the pink-colored face-sharing octahedra. The same 1D chain has been boxed in both viewing directions to emphasize the corner-sharing connectivity. 

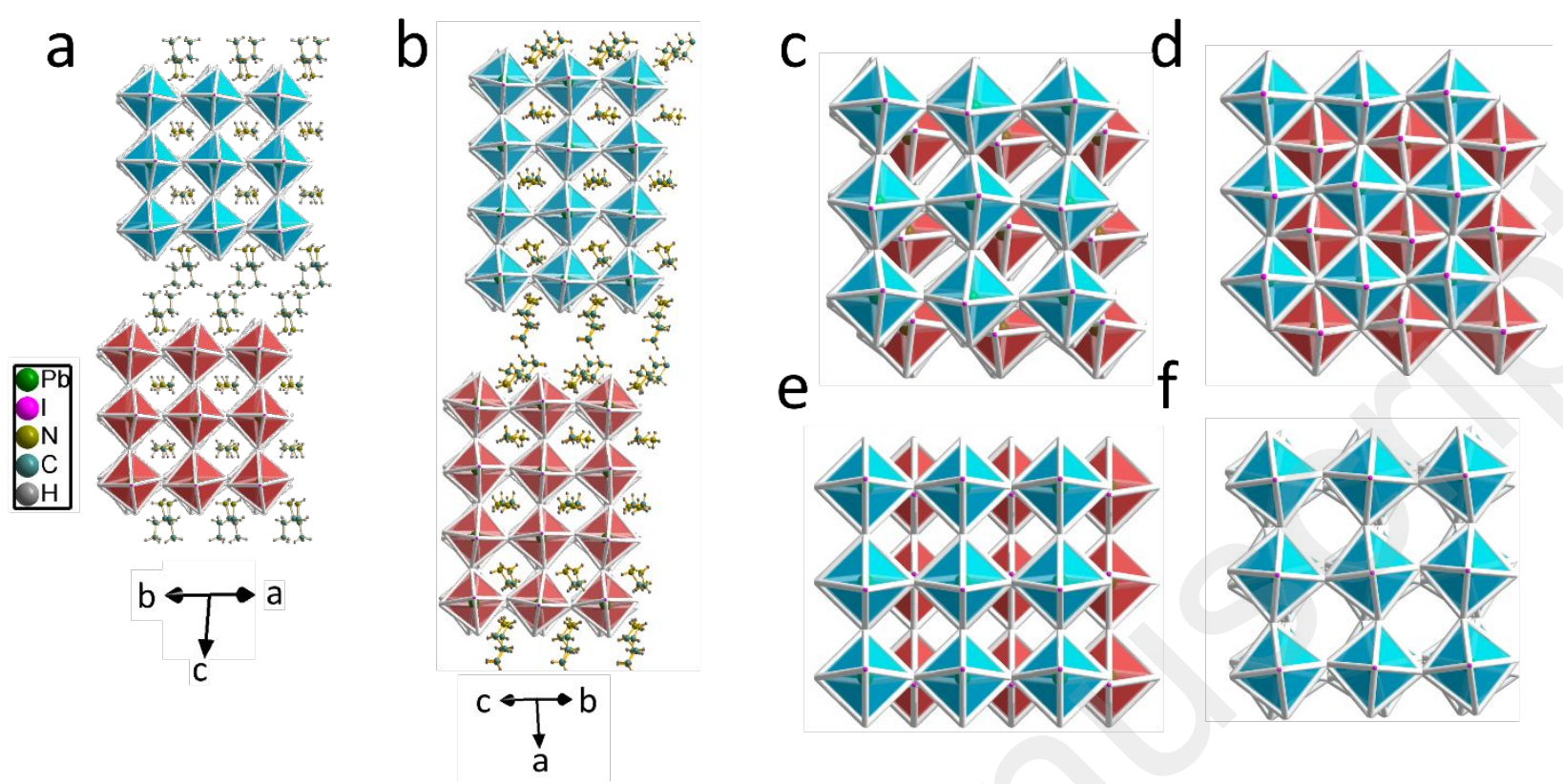

Figure 3. (a,b) The $n=3$ and $n=4$ Ruddlesden-Popper materials. (c-f) The alignment of the inorganic layers for various cations, all using $n=3$. Two layers are shown with the top layer in blue and the bottom in red, with the layers aligned so that the layers themselves are perpendicular to the viewing direction to give a better view of the alignment of the layers. (c) PA. (d) BA. (e) GA. (f) 3-AMP. 


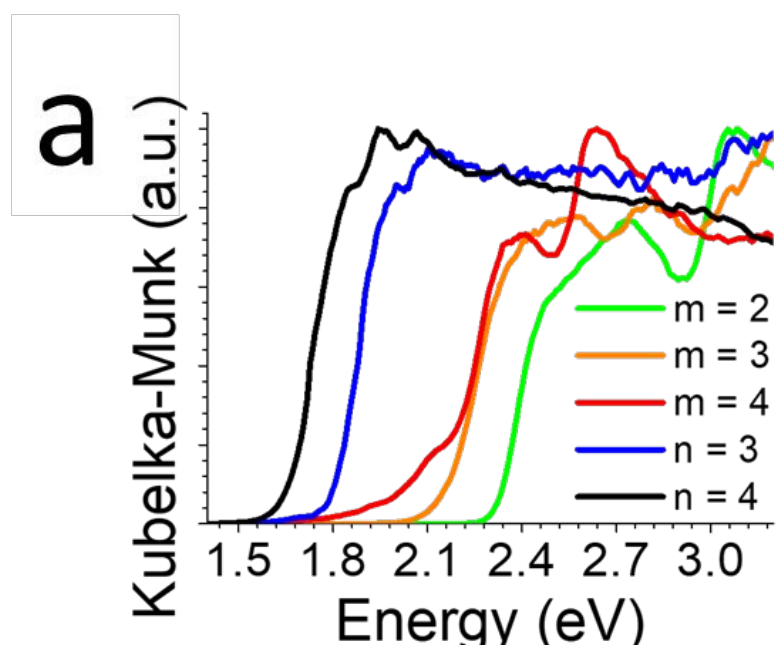

b

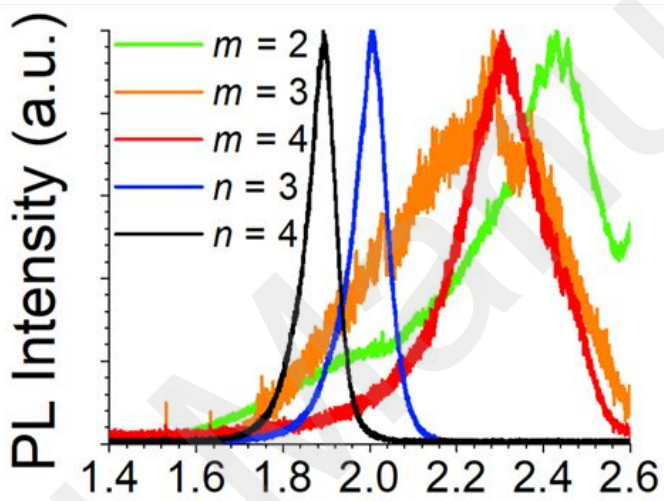

Energy (eV)

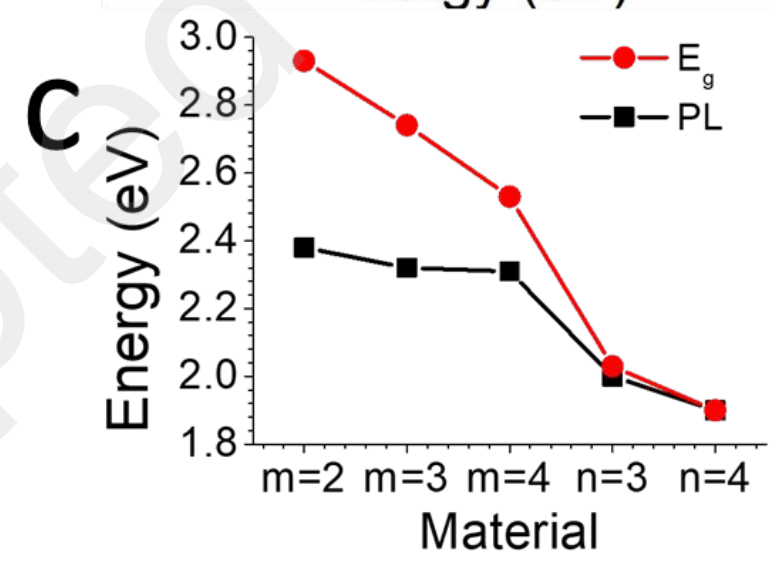

Figure 4. Optical properties of the PA based materials. The intensity of (a) and (b) have been normalized for comparison purposes. However, due to the weak intensity of the emission, spikes can be seen in the data, which are merely artifacts of the instrument. (a) The Kubelka-Munk Plot for the crystals showing the blue shift of the SL structures compared to the RP strucrures. (b) The photoluminescence for each of the crystals. (c) A comparison of the bandgaps and photoluminescence for the PA series. 

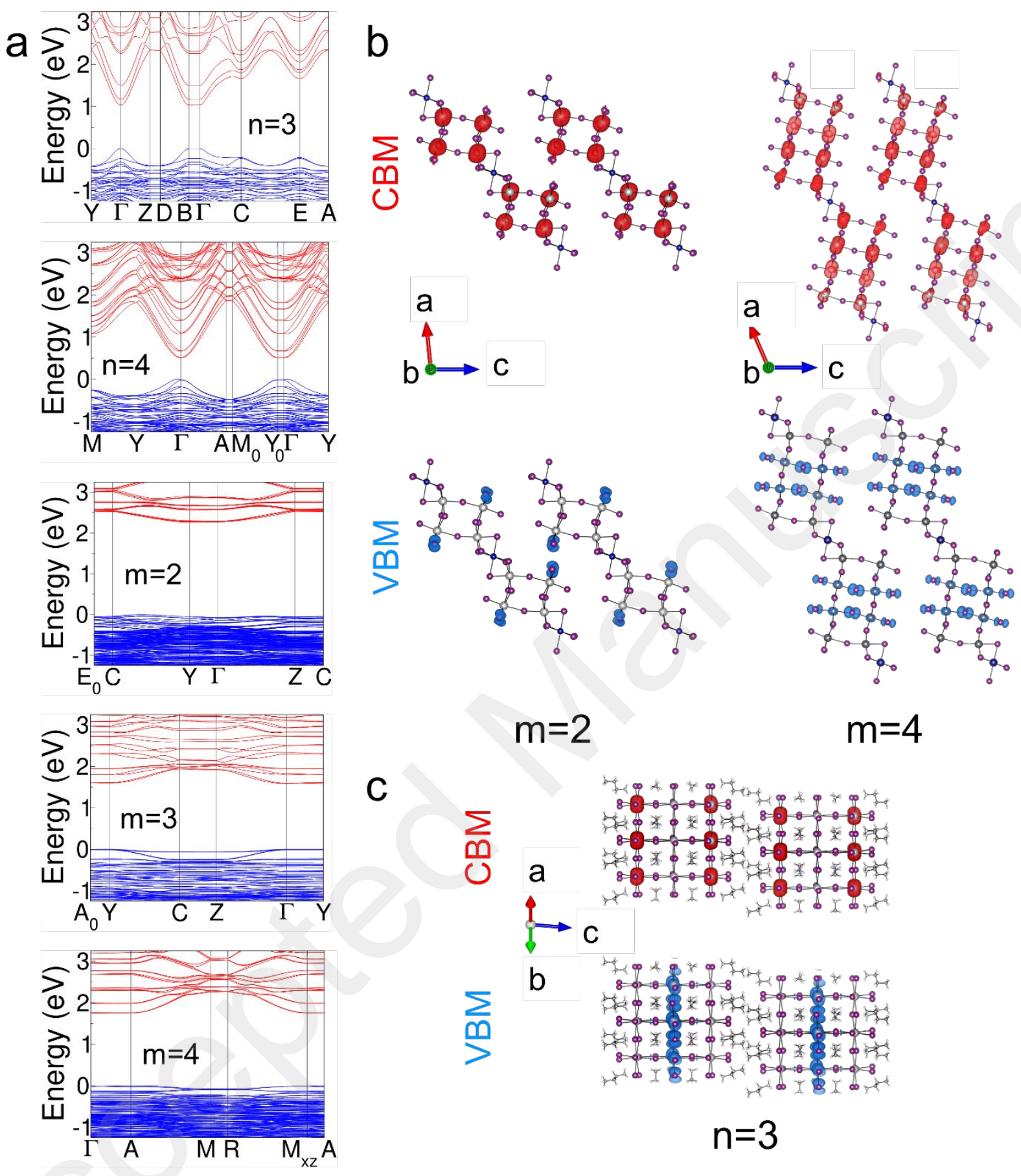

C

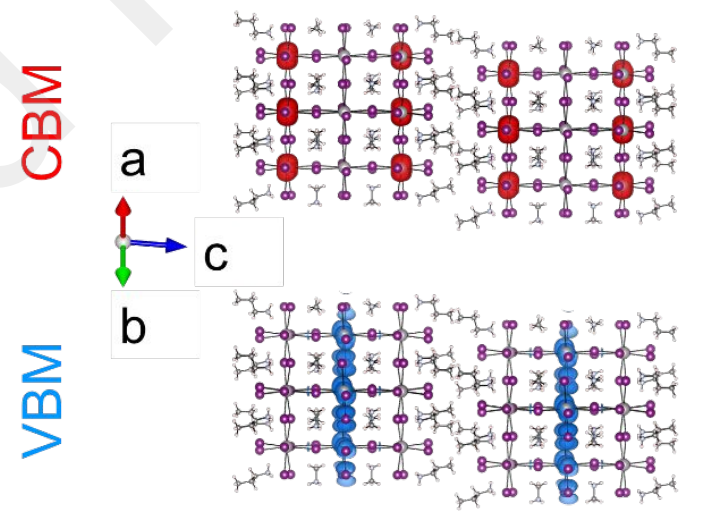

$n=3$

Figure 5. (a) Electronic band structures of the PA series. (b) Partial charge densities computed at the CBM (top, red) and VBM (bottom, blue) for $\mathrm{m}=2$ and $\mathrm{m}=4$, showing the localization of electronic density between the face-sharing octahedra. (c) Same for the CBM (top, red) and VBM (bottom, blue) of $\mathrm{n}=3$. 


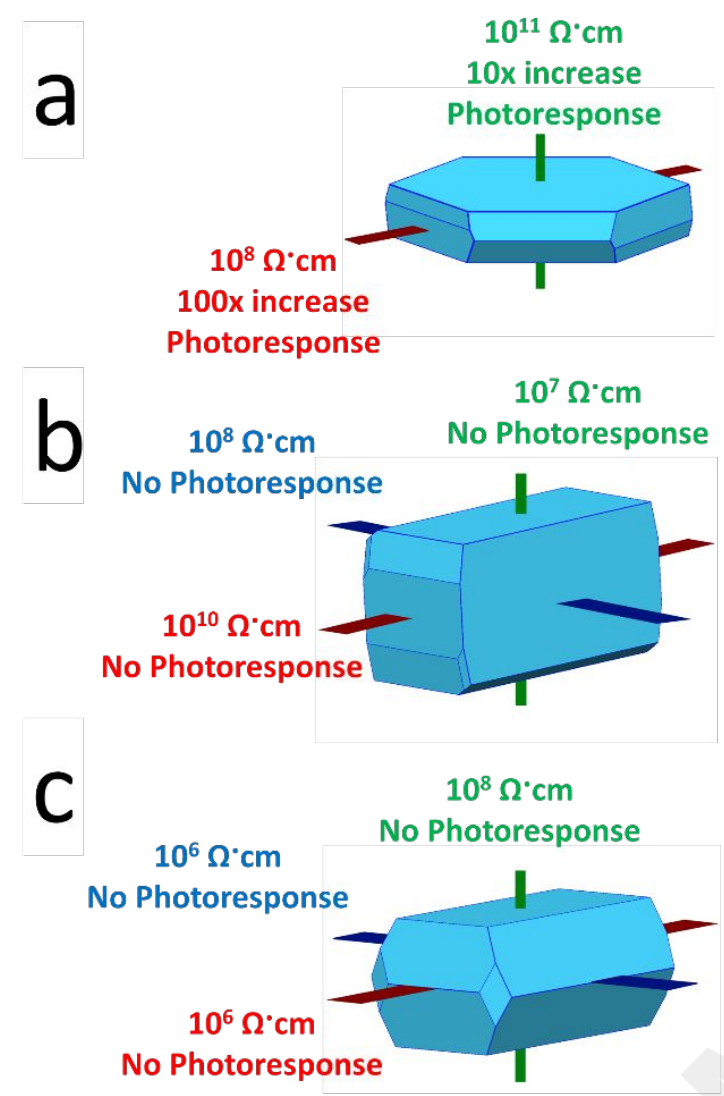

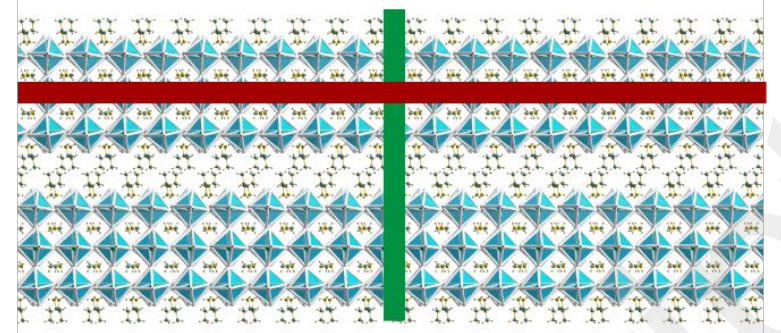
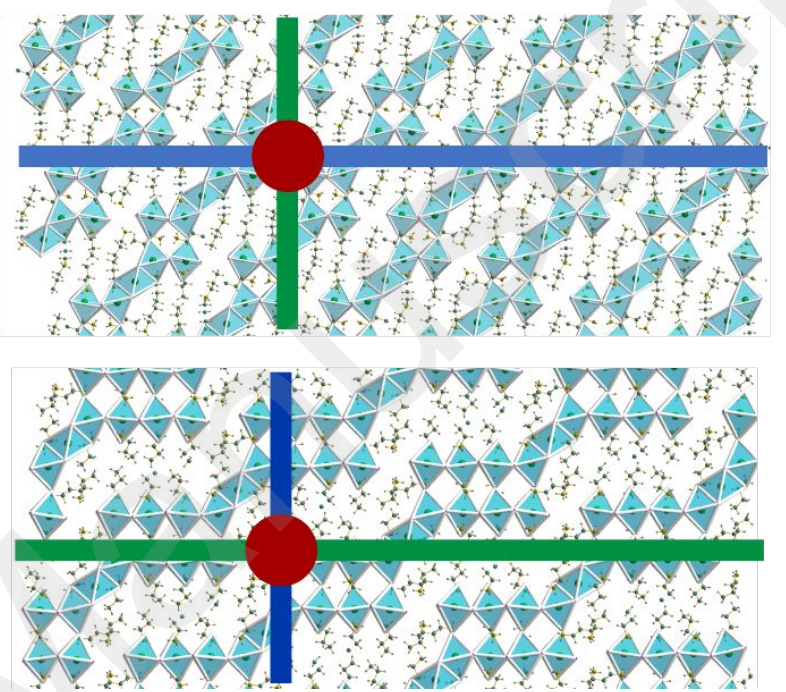

Figure 6. Resistivity measurements for (a) $n=3$, (b) $m=2$, and (c) $m=4$. The top row shows simulated crystal shapes created in Mercury and the various directions tested for each material. The lines simulate the wires attached to each material and the color of each line correlates to the images in the bottom row, showing the direction in the structure. Photoconductivity is shown in the top row based on how much decrease in resistivity was measured. Note that, for $m=2$, the green and blue directions (the sides of the needle) could not be discerned experimentally, so these two directions were assigned arbitrarily. 

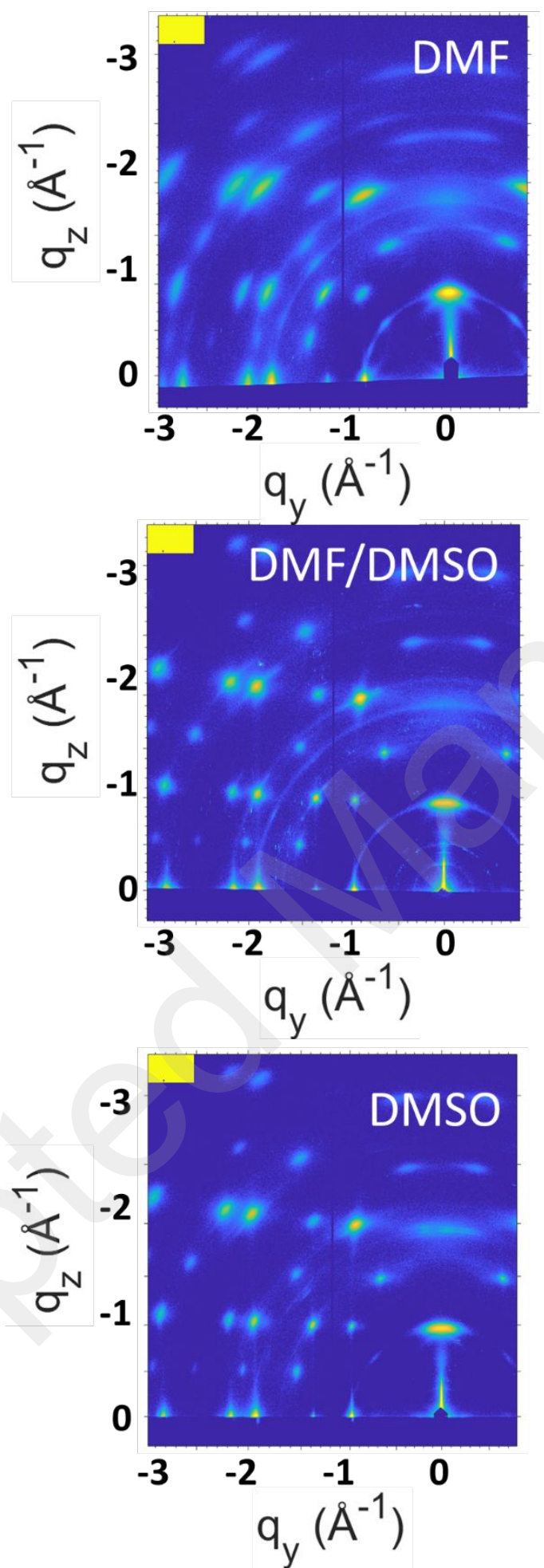

Figure 7. GIWAXS of the thin films of the $\mathrm{n}=3$ material using various concentrations of DMSO in DMF. 

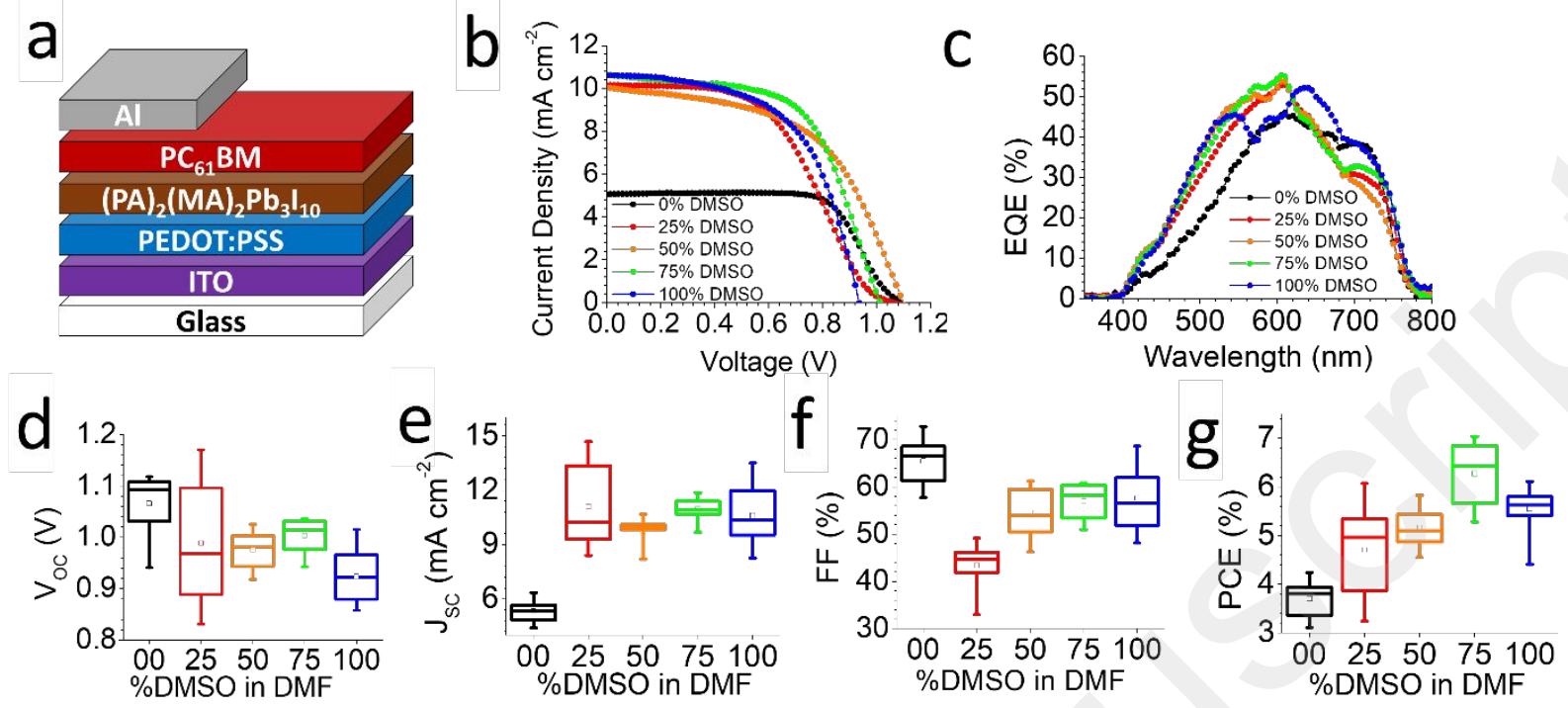

Figure 8. Solar cell devices made from $n=3$. (a) The device architecture used here. (b) Representative device curves using different concentrations of DMSO in DMF. (c) EQE of the devices. (d-g) Statistics from ten devices on $\mathrm{V}_{\mathrm{OC}}, \mathrm{J}_{\mathrm{SC}}, \mathrm{FF}$, and PCE, respectively. 

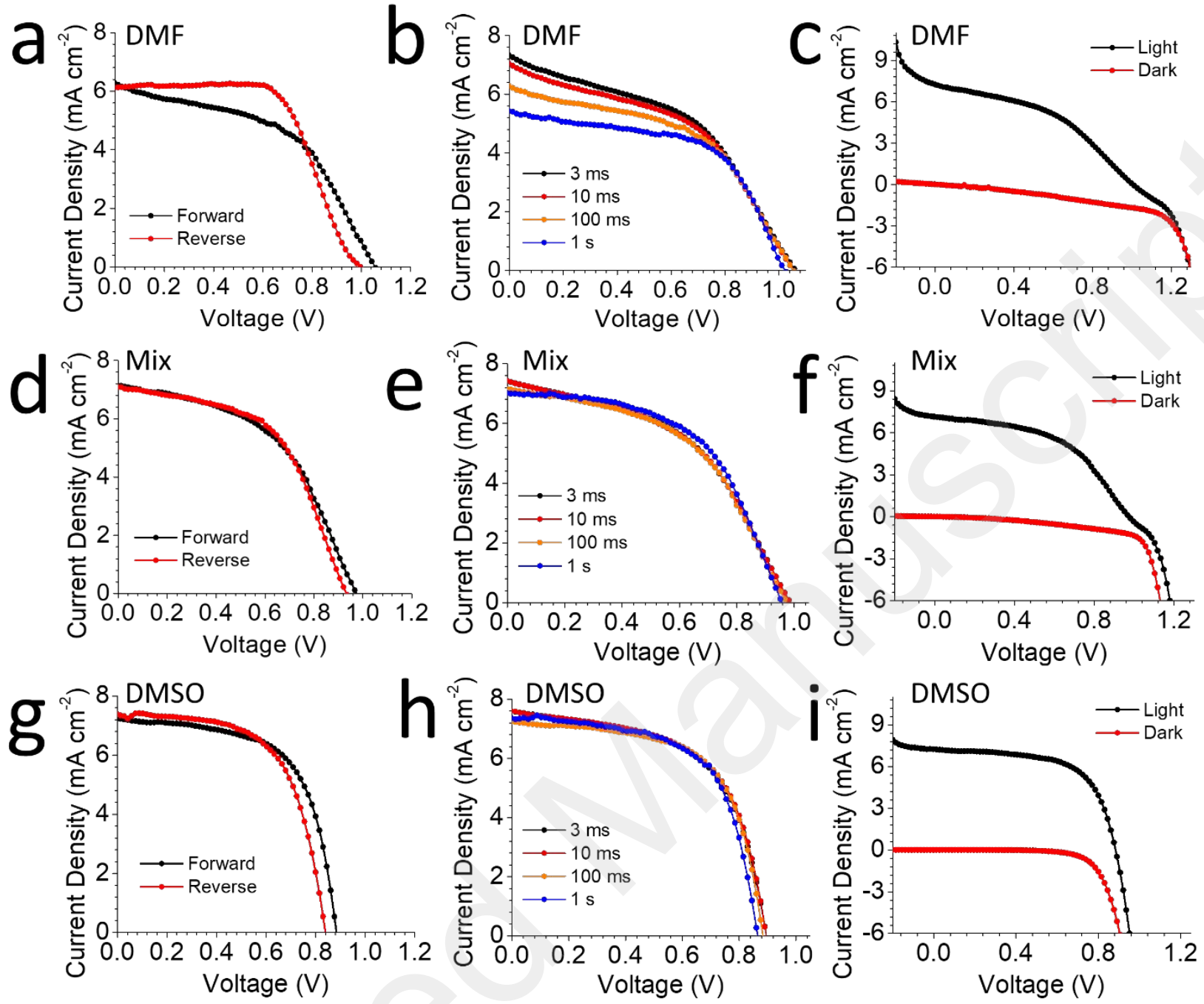

Figure 9. Device analysis for the $\mathrm{n}=3$ solar cells. (a-c) The devices made with pure DMF solutions show a high degree of hysteresis based on scan direction and scan speed as well as low $\mathrm{R}_{\mathrm{SH}}$ and high $\mathrm{R}_{\mathrm{S}}$. (d-f) Devices with 50\% DMSO/ 50\% DMF show little hysteresis and less leakage. (g-i) Devices with pure DMSO have negligible hysteresis, leakage, and series resistance. 
TOC Graphic:

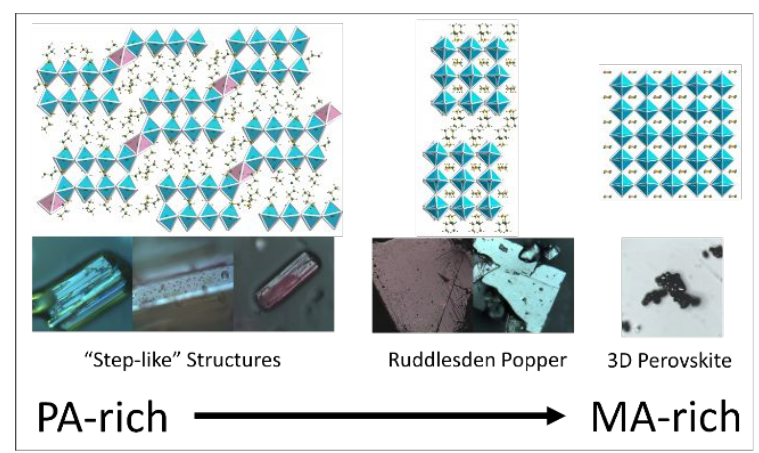

